\title{
Evaluating the impact of dredging strategies at tidal inlets: performance assessment
}

\author{
Carmen Zarzuelo ${ }^{\mathrm{a}}$, Alejandro López-Ruiz ${ }^{\mathrm{a}, *}$, Miguel Ortega-Sánchez ${ }^{\mathrm{b}}$ \\ ${ }^{a}$ Departamento de Ingeniería Aeroespacial y Mecánica de Fluidos, Universidad de \\ Sevilla, Camino de los Descubrimientos s/n, 41092, Seville, Spain \\ ${ }^{b}$ Andalusian Institute for Earth System Research, University of Granada, Avda. del \\ Mediterráneo, s/n, 18006, Granada, Spain
}

\begin{abstract}
Despite relevant advances achieved in recent years, sediment transport and sedimentation problems at tidal inlets are still worldwide issues to be addressed. Furthermore, dredging strategies are carried out following traditional layouts, such as channel deepening, lasting short periods of time despite the high economic expenditures and the potential environmental impacts. This work proposes a new dredging strategy for tidal inlets and analyzes its morphodynamic evolution by means of numerical modeling. This numerical model, used to perform hydro-morphodynamic simulations, is applied to a highly altered tidal inlet (Punta Umbría inlet, Southern Spain) with a navigational capacity being continuously compromised. After calibrated and tested, the model is applied to different dredging strategies, including channel deepening, littoral drift barrier and shoal removal. Among these strategies, the shoal removal, which is a new soft-engineering strategy, is found to be the most efficient to improve the navigational channel oper-
\end{abstract}

\footnotetext{
*Corresponding author alopez50@us.es
} 
ativity, defined as the percentage of navigable hours per year for different vessel drafts; this operativity improves up to $60 \%$ compared to the other strategies. This solution, which reduce the frequency of maintenance interventions and hence the environmental impacts, may be suitable for other inlets with compromised navigational capacities due to the presence of ebb shoals. The relation between the main maritime drivers and the morphodynamic changes is analyzed, concluding that the morphodynamic evolution of the navigational channels is closely related not only to the wave energetic content, but largely to the wave directionality. Finally, the shoal removal also increases the flow velocities at the inlet modifying the stability of the mouth and hampering its long-term closure. The potential environmental impacts derived from the shoal removal are also discussed.

Keywords:

navigational channel, morphodynamics, dredging strategy, numerical model, operativity, environmental impact

\section{Introduction}

Tidal inlets constitute the hydraulic connection between the open ocean 3 and coastal environments such as estuaries, rivers or bays, among others 4 (Militello and Kraus, 2001; Ray, 2001). They are frequently used for human

(Davis and Fitzgerald, 2004; Seminack and McBride, 2018). Moreover, tidal 

${ }_{34}$ McLean, 2018). 2015).

inlets are essential for shore and dune processes and the exchange of both water and sediments (Fortunato et al., 2014). Their dynamics are mainly controlled by complex interactions between different drivers (wind, tides, or waves) and the interactions with their own topographic features (Vikas et al.

All these interactions are the main reason of the tidal inlet stability and morphodynamics, determining also the evolution of human interventions. Among these interventions, the commercial and/or recreational exploitation of ports located inside tidal inlets usually requires periodic dredging works to maintain minimum water depths along the navigational channels assuring their operational capacity. These dredging works not only impact the economy of public administrations, driving also environmental impacts derived from the sand removal and the associated increase in suspended sediment Varriale et al. 1985; Brown et al., 1990; Wilber and Clarke, 2001; Harff et al., 2009, Oberle et al., 2014).

Given the significant sediment transport rates and the rapid morphodynamic variations at tidal inlets, the life-time of the dredging strategies around ebb tidal shoals is generally reduced to some years (in some cases pnly months) thus increasing the predicted impacts of these activities (Je et al., 2007; Dabees and Kraus, 2008; Wang et al., 2014b a). Hence, improving the understanding of the tidal inlet dynamics, the complex processes herein, and the morphodynamic evolution of dredging strategies is essential for the sustainable management of these coastal areas in view of reducing the dredging maintenance costs (Knowles and Cayan, 2004; Hinwood and 
While a number of studies have evaluated the stability of tidal inlets through the analysis of the sediment dynamics (Bales and Holley, 1989; Roman et al., 1997; Duong et al., 2016; Hinwood and McLean, 2018), the efficiency and impact of dredging strategies have received much less attention (Van Maren et al., 2015). These dredging activities, mainly designed to maintain the navigation requirements, frequently alter the natural environment (Montero et al., 2013) and imply extracting millions of cubic meters of sand and gravel (annually) in developed countries (Meng et al., 2018). Furthermore, the excavation, transportation and disposal of these sediments may lead to various adverse impacts on the marine environment (Erftemeijer and Robin Lewis, 2006), that can be especially relevant when dredging or disposal are performed in the vicinity of sensitive marine environments, such as coral reefs (Erftemeijer et al. 2012) and seagrass beds (Erftemeijer and Robin Lewis, 2006).

One of the few analyses on the efficiency of dredging activities was performed by Garel (2017), who studied the relation between dredged volumes and the frequency of maintenance operations at the Guadiana ebb tidal delta using a simplified version of the Inlet Reservoir Model (Kraus, 2000; Álvarez et al., 2017). More recently, Reyes-Merlo et al. (2017) proposed a new dredging strategy based on the reduction of the flow energy fluxes and its divergence, although neither its performance nor the sediment transport were analyzed in detail. There are two main reasons for this small number of studies: (1) the performance assessment of dredging strategies using numerical models is challenging due to the complexity of the simultaneous simulation of different drivers, and (2) these simulations require robust and reliable mor- 
phodynamic predictions, demanding an accurate calibration and testing of the model.

The main objective of this work is to define a new efficient dredging strategy, analyzing its morphodynamic evolution by means of numerical modeling. The efficiency of the strategy is measured in terms of navigational capacity and operativity of the main navigation channels for different vessel drafts. This operativity is defined as the percentage of navigable hours per year for different vessel drafts. The model is calibrated and tested both for hydro- and morphodynamics using mid-term simulations and multi-beam bathymetries. Different alternatives of dredging strategies are simulated with the model, including channel deepening, littoral drift barrier and shoal removal, which is a new soft-engineering strategy previously proposed by Reyes-Merlo et al. (2017) but which efficiency was not analyzed. This strategy may be suitable for any other tidal inlet where the presence of an ebb shoal compromise the navigational capacity. The performance of the strategies is assessed obtaining the operativity on the main navigational channels. Finally, the relation between the main maritime drivers and the morphodynamic evolution, as well as the potential hydrodynamic and environmental impacts, are discussed for the most efficient strategy. The methodology is applied to Punta Umbría inlet (Southern Spain), a highly human-altered environment where the navigation capacity is continuously compromised despite the frequent dredging strategies. This area constitutes a prototypical navigable inlet affected by the presence of an ebb tidal shoal where periodic dredging works are carried out. 


\section{Study site}

The Ría de Huelva is a shallow mesotidal estuary, located on the southwestern Spanish coast facing the Gulf of Cádiz $\left(37^{\circ} 11^{\prime} N, 6^{\circ} 57^{\prime} \mathrm{W}\right.$; Fig. 1). It occupies an area of $250 \mathrm{~km}^{2}$ including intertidal zones, the intersection of two main rivers (Tinto and Odiel) and the Punta Umbría inlet (PUI hereinafter). The Tinto River (Fig. 1) has a length of $100 \mathrm{~km}$ with a drainage basin of $720 \mathrm{~km}^{2}$, whereas the Odiel River (Fig. 1) flows $140 \mathrm{~km}$ until the mouth of the estuary (Sainz et al., 2004).

PUI is an $8 \mathrm{~km}$ long (NW-SE) and $0.5 \mathrm{~km}$ wide (SW-NE) channel with a maximum depth of $12 \mathrm{~m}$ below mean sea level (MSL hereinafter). It is an ebb-tidal system with minor ebb channels, shoals and frontal lobes (ReyesMerlo et al., 2017), which is characterized by large salt marshes with a high density of shallow meandering tidal creeks, sand flats and a complex network of natural and partially dredged channels. Its mouth is bound at the Atlantic Ocean side by a littoral barrier and a mixture of sandbanks and highly mobile shallow channels with depths of 2-3 m respect to MSL (Barba-Brioso et al. 2010). The PUI system is characterized by the presence of an ebb shoal with a averaged water depth of $3 \mathrm{~m}$ respect to MSL (Fig. 11d). The shoal slightly migrated to the East during last decades due to the dredging works performed in the area (Reyes-Merlo et al., 2017). The presence of this shoal have caused navigational problems at PUI for decades, promoting the construction of a jetty in the mid 80's of the 20th century at the western side of the inlet mouth, extending to approximately $4 \mathrm{~m}$ depth. Two navigational channels, $\mathrm{NC}-\mathrm{W}$ and $\mathrm{NC}-\mathrm{E}$ in Fig. $1 \mathrm{~d}$, are used by the local vessels to cross the shoal towards the two main port areas along PUI (Fig. 11). 
Morales et al. (2014) analyzed the sedimentary evolution of the PUI environment, pointing out that it has been intensified by recent human interventions with extensive and intense dredging works performed during the last years with the aim of avoiding the closure of the inlet and the silting of the channel. Different designs of navigational channel deepening have been carried out, although they had a limited life-time (up to 4 years) and have been unable to resolve the navigational issues at PUI (Reyes-Merlo et al. 2017).

Tidal data obtained from a tidal gauge (REDMAR 3329, Puertos del Estado, Spanish Ministry of Public Works), located at Huelva Port (Fig. 1), indicate that tides are semi-diurnal with a tidal range varying between 1 and $4 \mathrm{~m}$. According to Rodríguez-Ramírez (2008) this tidal range controls the hydrodynamics and sediment transport in the area. Furthermore, ReyesMerlo et al. (2017) found that tide-induced currents can reach $1.2 \mathrm{~m} / \mathrm{s}$ and $0.8 \mathrm{~m} / \mathrm{s}$ at its mouth during ebb and flood, respectively. Different works (Muñoz et al., 1997; Sainz and Ruiz, 2006, Ruiz et al., 2014) concluded that the morphological framework of the PUI is controlled by the tides in the deeper channels where silt and clay are deposited, whereas in the middle part of the PUI other factors such as wind waves, the presence of vegetation or the weak fluvial action affect the sediment dynamics. At the South of the PUI, the morphology is largely influenced by wind and swell waves. This variability has an effect on the sediment distribution, which is coarser $\left(D_{50}\right.$ $\approx 2 \mathrm{~mm})$ upstream and finer $\left(D_{50} \approx 0.53 \mathrm{~mm}\right)$ downstream.

The local wave climate, obtained from the hindcast data of SIMAR 1052048 (Puertos del Estado, Spanish Ministry of Public Works, Fig. 1), is 
characterized by moderate sea states (wave heights and periods in the range 0.5-1 $\mathrm{m}$ and 4-6 s, respectively), predominantly approaching from West to the Southwest. Storms typically approach PUI from Southwest with wave heights between 3 and $6 \mathrm{~m}$. This wave climate results in a local net longshore sediment transport to the west of approximately $0.5-3 \times 10^{5} \mathrm{~m}^{3} /$ year (CEDEX, 2013; Reyes-Merlo et al., 2015). Furthermore, according to I.E.O. (1992) and Muñoz et al. (1997) the highest runoffs occur from December to February for both rivers, with averaged discharges of $38.6 \mathrm{~m}^{3} / \mathrm{s}$, whereas the lowest are concentrated during the summer months $\left(\leq 0.4 \mathrm{~m}^{3} / \mathrm{s}\right)$. FIGURE 1

\section{Materials and methods}

\subsection{Bathymetry and topography data}

Between 2002 and 2015 regular bathymetric surveys were carried out at the mouth and dredged channels of PUI to control the maintenance (dredging) works of the navigational channels. A total of 18 multi-beam bathymetry surveys were provided by Agencia Pública de Puertos de Andalucía (APPA, Andalusian Regional Government), although the majority of the dataset only covered some cross-sections of the dredged area along the main navigation channel (NC-E). The spatial resolution of the bathymetries is $2 \times 2 \mathrm{~m}$, and data were corrected and referenced to the MSL at the study site using water levels from the tidal gauge REDMAR 3329 (Fig. 1).

APPA bathymetries covering the complete PUI were used in the analysis, being completed with offshore bathymetry data provided by the Hydrographic Marine Institute (IHM, Spain) with a spatial resolution of $5 \times 5$ 
m. The topography close to the inlet was defined with data from a Digital Elevation Model (DEM, provided by National Geographic Institute, Spain) with a resolution of $5 \times 5 \mathrm{~m}$ at tidal flats and $25 \times 25 \mathrm{~m}$ elsewhere.

\subsection{Field survey}

Field measurements of water levels, currents and wave heights were used to calibrate and test the numerical model. The survey was carried out during the spring 2014 collecting data at 5 locations along the main channel of PUI and the inner continental shelf with 4 current profiles (ADCP hereinafter) and 1 tidal gauge (Fig. 1). Instruments were deployed on May 2014 and retrieved on June 2014. For further details on the survey the reader is referred to Reyes-Merlo et al. (2017).

\subsection{Numerical model}

The Delft3D model, which is a finite-difference numerical model developed by WL/Delft Hydraulics and Delft University of Technology (Lesser et al., 2004), was used to study the PUI hydro-morphodynamics. It is a widely used computational model to simulate the main physical processes that are relevant in coastal environments, such as embayments and estuarjes (Van Leeuwen et al., 2003; Van Rijn, 2007; Ruggiero et al., 2009; Iglesias et al., 2012; Hansen et al., 2013). We used two modules of the model: FLOW and WAVE. The former is based on the two dimensional (depth-integrated) Navier-Stokes equations for an incompressible fluid under the shallow water and the Boussinesq assumptions. It also includes morphodynamic evolution equations, for which the total transport is obtained as the sum of bed and suspended load transports based on the depth-integrated advection-diffusion 
equation (Van Rijn, 1993). These transports rates are obtained for different sediment fractions, which can be cohesive or non-cohesive and are defined using their densities and sizes. Bed shear stress calculation is based on the Van Rijn (2007) roughness predictor. The bed level is updated during each time step of the flow computation, considering the exchange with the suspended sediment transport and the gradient of the bed load transport.

ـ The WAVE module implements the SWAN model (Booij et al., 1999, Ris et al. 1999) for the wave propagation. The model solves the spectral action balance equation using finite differences for a spectral or parametric input (as in our case) specified along the grid boundaries. It accounts for wave generation, propagation and dissipation for arbitrary wind, bathymetry and currents. To achieve an accurate cross-shore distribution of the wave forces, the wave energy balance equation is solved together with the roller energy balance within the flow module during each flow time step (Reniers et al., 2004).

Although Reyes-Merlo et al. (2017) previously implemented, calibrated and tested the DELFT3D model in the study site to obtain the hydrodynamics, we used a new set of grids to improve the computational efficiency reducing the computing times, which is key for the more demanding morphodynamic simulations. To assure the validity and robustness of the results, the model was first re-calibrated and tested for the hydrodynamics for a longer period than previous studies (Reyes-Merlo et al., 2017), and then calibrated and tested for the morphodynamics for the first time in the area. 


\subsubsection{Model setup}

The computational domain consists of two nested curvilinear grids. The coarser grid (Fig. 1, blue line) has an averaged resolution of $200 \times 200 \mathrm{~m}$ and extends down to the continental shelf break to minimize boundary effects of the wave propagation across the shelf. This grid is only used for the WAVE module. The nested grid (Fig. 1, red line) couples both modules with a resolution ranging between $30 \times 30$ and $45 \times 45 \mathrm{~m}$ to accurately capture the morphological changes. Following Reyes-Merlo et al. (2017), the river discharges were neglected due to their low inflow rates. The results obtained with the model showing maximum suspended sediment concentrations consistently at the inlet, demonstrate that the inlet is wave-dominated.

Similarly to previous studies (Lesser et al., 2004; Eelkema et al., 2012; Dissanayake and Wurpts, 2013, Luijendijk et al., 2017), the morphodynamic module was found to be very sensitive to the median sediment diameter. According to the data provided by APPA at 8 locations equally distributed along the main PUI channel, two different sets of sediments were defined, with $D_{50} \approx 2 \mathrm{~mm}$ at the upstream area of the inlet and $0.53 \mathrm{~mm}$ downstream. According to previous works (Nienhuis et al., 2016), the suspended bed load and wave-related suspended sediment transport factors were defined as 1 and 0.5 , respectively. Considering the numerical restrictions of the model (courant number), the time step was defined as $0.1 \mathrm{~min}$.

\subsubsection{Calibration and testing: hydrodynamics}

Data from the ADCPs and tidal gauge (3.2) were used to calibrate the model over the period May 30th to June 4th, 2014; then it was validated from June 5th to June 9th, 2014. These periods, longer than those used in 
Reyes-Merlo et al. (2017), were chosen because they included a spring-neap cycle (May 30th to June 3rd and June 3rd to 9th, respectively), ensuring the performance of the model independently of the tidal conditions. Unperturbed initial conditions of water levels and velocities were specified with a warm-up period of 2 days in which the maritime and wind forcing smoothly increased from the initial conditions to their real values.

Forcing and initializing a numerical model remains one of the key elements for the precise calibration with field data and consequently obtaining reliable model results. In this case, from the regional models of barotropic tide (Egbert and Erofeeca, 2002), thirteen dominant constituents were considered for the tidal levels at the open-sea boundaries of the nested grid. Following the methodology applied in Zarzuelo et al. (2015, 2017, 2018), different values of bed roughness and wind drag coefficients were tested to improve the calibration.

Preliminary simulations for spatially-uniform values of the Chézy coefficient were carried out, but the calibration of simultaneous water levels and currents was not satisfactory. Then, a spatially-variable roughness was defined according to Cheng et al. (1993) and Dias and Lopes (2006a), defining the roughness coefficient as a function of water depth (Dias and Lopes, 2006b; Dias et al., 2009). The final values for this coefficient (Table 1) are similar to those in Geyer et al. (2000). For the wind-induced hydrodynamic response, the wind data were obtained from SIMAR 1052048, calibrating the drag coefficient with the expressions in Smith et al. (1992) and Dias and Lopes (2006b).

For the WAVE module, the spectral resolution of the frequency space 


\begin{tabular}{cc}
\hline Water depth $(\mathbf{m})$ & Chézy \\
\hline \hline $0 \leq \mathrm{h}<3$ & 22 \\
$3 \leq \mathrm{h}$ & $\left.\mathbf{s}^{-1}\right)$ \\
$3 \leq \mathrm{h}<6$ & 35 \\
$6 \leq \mathrm{h}<9$ & 70 \\
$9 \leq \mathrm{h}$ & 100 \\
\hline
\end{tabular}

Table 1: Bottom roughness coefficients.

was defined with 37 and 24 logarithmically distributed frequencies ranging from 0.03 to $1 \mathrm{~Hz}$ for the coarser and nested grid, respectively. For the directional space, 72 (coarser grid) and 36 (nested grid) directions were used. Deep-water wave conditions from the SIMAR 1052048 (Fig. 1) were used as parametric boundary conditions of wave spectrum.

Fig. 2 shows the results for water level, East velocity, North velocity and significant wave height for both the calibration and testing periods at the ADCP located at A1 (Fig. 1) whereas Table 2 summarizes the results for the rest of the instruments including both the calibration and testing periods. The statistical indicators used are root mean square errors ( $R M S E)$, correlation coefficients $(R)$ and skill coefficients $(S)$. For all cases, excellent (good) agreements between measured and modeled water levels (currents) were obtained. The best model results were achieved for the stations closer to the PUI mouth. We also obtained a good correlation between modeled and recorded significant wave heights. The standard deviations between the modeled results and observations also fell within a reasonable range according to Lesser et al. (2004); Iglesias and Carballo (2009); Elias and Hansen (2012); Iglesias et al. (2012), and improve those obtained previously in the 


\begin{tabular}{|c|c|c|c|c|c|c|c|c|c|c|c|c|}
\cline { 2 - 14 } \multicolumn{1}{c|}{} & \multicolumn{3}{c|}{ Water Level $(\mathrm{m})$} & \multicolumn{2}{c|}{ East Velocity $(\mathrm{m} / \mathrm{s})$} & \multicolumn{2}{c|}{ North Velocity $(\mathrm{m} / \mathrm{s})$} & \multicolumn{3}{c|}{ Wave height $(\mathrm{m})$} \\
\cline { 2 - 14 } \multicolumn{1}{c|}{} & $R M S E$ & $R$ & $S$ & $R M S E$ & $R$ & $S$ & $R M S E$ & $R$ & $S$ & $R M S E$ & $R$ & $S$ \\
\hline $\mathrm{A}_{1}$ & 0.06 & 0.99 & 0.99 & 0.04 & 0.80 & 0.83 & 0.03 & 0.83 & 0.77 & 0.14 & 0.75 & 0.70 \\
\hline $\mathrm{A}_{2}$ & 0.07 & 0.99 & 0.99 & 0.05 & 0.80 & 0.91 & 0.26 & 0.96 & 0.50 & $\mathbf{X}$ & $\mathbf{X}$ & $\mathbf{X}$ \\
\hline $\mathrm{A}_{3}$ & 0.09 & 0.99 & 0.99 & 0.25 & 0.69 & 0.67 & 0.09 & 0.87 & 0.64 & $\mathbf{X}$ & $\mathbf{X}$ & $\mathbf{X}$ \\
\hline $\mathrm{A}_{4}$ & 0.10 & 0.99 & 0.99 & 0.12 & 0.79 & 0.85 & 0.12 & 0.79 & 0.50 & $\mathbf{X}$ & $\mathbf{X}$ & $\mathbf{X}$ \\
\hline
\end{tabular}

Table 2: Root mean square errors $(R M S E)$, correlation coefficients $(R)$ and skill coefficients $(S)$, for the calibration and testing periods at $\mathrm{A}_{1}, \mathrm{~A}_{2}, \mathrm{~A}_{3}$ and $\mathrm{A}_{4}$.

area by Reyes-Merlo et al. (2017).

\section{FIGURE 2}

\subsubsection{Calibration and testing: morphodynamics}

To calibrate the morphodynamic simulations, the model was run for a 20 day period (March 7th to March 27th, 2015) using the parameters defined in 3.3.2. This period was chosen because: (1) according to the climate data, high wave heights and water levels occurred simultaneously, resulting in high rates of sediment transport; (2) there are suitable bathymetric data available both for the initial and final dates; and (3) its duration is sufficient to capture the morphological feedback between sediments and hydrodynamics with a reasonable computational cost. The suspended and bedload sediment transport considered the oscillatory current and wave motion. Table 3 summarizes the values obtained for the calibrated parameters of the morphodynamic simulations. Finally, the model was tested during a longer 2-month period (from March 25th to May 23rd, 2002) and results were compared with the available bathymetric measurements for these dates.

Results show good agreement between the simulated and measured bed 


\begin{tabular}{cc}
\hline \multicolumn{2}{c}{ Transport and Bed Updating } \\
\hline \hline Initial sediment layer thickness at bed $(\mathrm{m})$ & 10 \\
Minimum depth for sediment calculation $(\mathrm{m})$ & 0.1 \\
Thereshold sediment thickness $(\mathrm{m})$ & 0.05 \\
van Rijn's reference height factor & 1 \\
Spin-up interval before morphological changes (min) & 7410 \\
\hline
\end{tabular}

Table 3: Summary of the main morphological parameters used in the numerical model.

level changes during the calibration and testing periods, with the model correctly reproducing the erosion/accretion and channel dynamics patterns. The observed sedimentation in the central part of the channel is well captured by the model, although at the end of the simulation period the channel is slightly deeper when compared to bathymetric data (Fig. 3). Besides, the erosion zones at the boundaries of the channel are also reproduced by the model. To assess the relative accuracy of the predictions, the mean-squared error based skill score (MSESS) (Murphy, 1988; Bosboom et al., 2014) was obtained. This parameter is defined as:

$$
\operatorname{MSESS}=1-\frac{\left\langle\left(\Delta z_{m}-\Delta z_{o}\right)^{2}\right\rangle}{\left\langle\Delta z_{o}^{2}\right\rangle}
$$

where the angle brackets indicate spatial weighted averaging and $z_{m}$ and $z_{o}$ are the modeled and observed bed levels, respectively. Even considering that fitting the morphodynamic predictions is very demanding, according to the classification of the accuracy based on the MSESS proposed by Bosboom et al. (2014) a good agreement was achieved between the simulated and 
observed bed evolution, with values of 0.66 (0.54) for the calibration (testing) periods.

FIGURE 3

\subsection{Dredging strategies}

According to Reyes-Merlo et al. (2017), the strong siltation caused by the litoral drift resulted in the growth of ebb shoal near the mouth of PUI after each channel deepening performed in the area, reducing its navigational capacity and requiring recurrent interventions. Thus, the present geometry of the shoal is influenced by past human interventions. In this work four different strategies were defined to improve the navigational capacity of the inlet and reduce the number and impact of the interventions. Among these strategies, the most efficient, i.e. the one that maintains the highest navigational capacity during a 3-month period, was chosen based on the results of the morphodynamic simulations. After that, we used the selected strategy to perform a deeper analysis of its morphodynamic evolution and its effects on the PUI hydrodynamics. The four strategies defined are characterized as follows.

\subsection{1. $S_{1}$ : PUI in 2014}

This first strategy does not imply any intervention in PUI. The bathymetry corresponds to the most unaltered configuration of the study site (Fig. 4a), since it was obtained after the longest period without dredging works in the area (4 years). According to the bathymetric dataset, it is the most natural configuration of PUI. 


\subsection{2. $S_{2}$ : Channel deepening}

This strategy deepen the main navigation channel in $\mathrm{S}_{1}$ (NC-E, Fig. 4b), similar to the past dredging works performed in PUI. It increases the water depth in the shallowest zone of the submerged sandbar of PUI to reduce its recurring siltation. The average dredged volume is $1.3 \times 10^{5} \mathrm{~m}^{3}$ and the dredged volume in the shoaling area represents $\approx 30 \%$ of all the mobilized material. The depth of the dredged channel is $4 \mathrm{~m}$ due to the maximum draft of the main vessels that navigate in the area.

\subsection{3. $S_{3}$ : Littoral drift barrier}

This strategy enlarges the jetty of the river mouth (Fig. 4p). The current jetty extends to approximately $4 \mathrm{~m}$ depth (respect to MSL), allowing the sediment bypass of the eastern-oriented littoral drift generated up-drift PUI, being the main reason for sedimentation in the channel. With this strategy, the jetty is extended to $8 \mathrm{~m}$ depth (300 $\mathrm{m}$ in length), which is approximately the closure depth of the adjacent beach, contributing to significantly reduce the sand bypass. This is the most expensive and long-term strategy, and can be used in combination with any other strategy. However, to simplify the analysis these combinations were not considered.

\subsection{4. $S_{4}$ : Shoal removal}

This strategy, originally proposed by Reyes-Merlo et al. (2017), consists of a leveling and partial removal of the shoal at the lee-side of the jetty (Fig. 44), to reduce the energy divergence and hence the sediment transport. The main goal of this solution is to extend the life-time of the intervention imitating how nature works, reducing the external gradients and hence minimizing 
the sedimentation at PUI. It is a soft alternative (no structures required) that promotes ecosystem services and the resilience of the system. The water depths are consistent with the requirements for navigation at PUI $(\simeq 4 \mathrm{~m}$ below MSL), with maximum differences between the initial and final profiles of $\simeq 2 \mathrm{~m}$. The total affected region covers $7.4 \times 10^{5} \mathrm{~m}^{2}$ and the volume of removed material is $2 \times 10^{5} \mathrm{~m}^{3}$ (Reyes-Merlo et al. 2017). This strategy is presented as a more natural-adapted and sustainable strategy in the mid to long-term maintenance of the inlet, being applicable to any other worldwide inlet with navigational issues derived from the presence of ebb tidal shoals. FIGURE 4

\section{Results}

\subsection{Efficiency of the strategies}

Morphodynamic simulations of the 4 strategies defined (Fig. 4) were performed by means of morphological evolution and operativity. The simulations span three months of a winter period with extreme wave climate conditions (December 22th, 2009 to March 20th, 2010).

Fig. 5 shows the wave, wind and water level climate during the 3-month period using the data from SIMAR 1052048 and REDMAR 3329 (Fig. 1). Three different phases in terms of wave climate can be defined: (1) a sequence of 4 important storms until the middle of January, (2) a period of approximately 20 days of milder wave energy conditions, and (3) another 20 days of consistent storm conditions with wave heights above $2 \mathrm{~m}$, storm surges up to $0.5 \mathrm{~m}$ and important wind velocities (red dashed boxes-Fig. 5).

During the entire period, waves predominantly reached PUI from the 
WSW with heights typically up to approximately $4 \mathrm{~m}$ at the peak of the storms. Wind directions were predominantly NW and NE with speeds varying between 2 and $15 \mathrm{~m} / \mathrm{s}$ and a monthly average close to $10 \mathrm{~m} / \mathrm{s}$. Given the energetic content of waves and winds, important bathymetry changes were expected.

FIGURE 5

\subsubsection{Morphodynamic evolution of the inlet}

Fig. 6 shows the bathymetric differences between the beginning and the end of the 3-month simulations for each strategy. Results were obtained not only over PUI (left panels), but also along the two navigational channels $\mathrm{NC}-\mathrm{W}$ and $\mathrm{NC}-\mathrm{E}$.

For $\mathrm{S}_{1}, \mathrm{~S}_{2}$ and $\mathrm{S}_{3}$ the erosion/accretion patterns are similar: erosion is concentrated at the surroundings of the main channel, specially at the eastern shoreline of PUI, whereas accretion is observed at large areas over the central part of the PUI where the NC transect. This is clearly observed in Fig. 6 (panels e and f) where the differences along NC are plotted: significant reductions of water depths are identified, specially for $\mathrm{NC}-\mathrm{W}$ where this reduction is above $10 \%$ of the initial water depth. Along these NC, erosion is only slightly present $(\simeq 3-5 \%)$ at the southern end of $\mathrm{NC}-\mathrm{W}$. These results highlight that $\mathrm{S}_{2}$ and $\mathrm{S}_{3}$ scarcely reduce the accretion at the southern end of $\mathrm{NC}-\mathrm{W}$, where the loss of water depth decreased $1 \%$ compared to the unaltered strategy $\left(\mathrm{S}_{1}\right)$.

Results are clearly different for $\mathrm{S}_{4}$ : although there is also a generalized accretion along the NC, water depths only reduced up to $3.5 \%$. The morphological changes are weaker compared to $\mathrm{S}_{1}$ and $\mathrm{S}_{3}$ even for the areas located 
outside the shoal removal area; furthermore, the water depth reduction observed at $\mathrm{NC}-\mathrm{W}$ for the other strategies is vanished. Hence, this strategy clearly reduces the morphodynamic variations and its gradients along the NC. Results are summarized in Table 4.

FIGURE 6

\subsubsection{Operativity}

Although $\mathrm{S}_{4}$ was found to be the most efficient strategy in terms of reducing the morphodynamic changes (i.e. less accretion), we quantified the effects of these changes on the navigational capacity of PUI assessing the operativity along the NC. We define the operativity as the percentage of time during the simulation period for which the minimum water depth along the complete $\mathrm{NC}$ is greater than a threshold value in correspondence to different vessel drafts. Hence, the operativity depends on the clearance at the minimum water depth point along the complete NC.

The results for each strategy are shown in Fig. 7, where the water depth of $3 \mathrm{~m}$ is highlighted with a vertical black line. According to local administrations, this value corresponds to the draft (including the safety clearance) of the design vessel expected to navigate along the NC of PUI. The operativities for $S_{1}$ and $S_{3}$ are closely related with the morphodynamic evolution obtained in Fig. (6), with values of approximately $60 \%$ and $40 \%$ for NC-E and $\mathrm{NC}-\mathrm{W}$, respectively, for $3 \mathrm{~m}$ water depth. The improvements on the operational capacity for $\mathrm{S}_{2}$ are very narrow and only perceptible for $\mathrm{NC}-\mathrm{W}$, where a slight increase of $\simeq 2 \%$ is observed. The operativity for vessels with drafts above $5 \mathrm{~m}$ is 0 using neither $\mathrm{NC}-\mathrm{W}$ or $\mathrm{NC}-\mathrm{E}$.

On the other hand, results for $\mathrm{S}_{4}$ highlight the improvement of the op- 


\begin{tabular}{|c|c|c|c|c|c|c|}
\hline & \multicolumn{2}{|c|}{ Max. erosion (\%) } & \multicolumn{2}{|c|}{ Max. accretion (\%) } & \multicolumn{2}{|c|}{ Operativity, $3 \mathrm{~m}(\%)$} \\
\hline Strategy & $\mathrm{NC}-\mathrm{W}$ & $\mathrm{NC}-\mathrm{E}$ & $\mathrm{NC}-\mathrm{W}$ & $\mathrm{NC}-\mathrm{E}$ & $\mathrm{NC}-\mathrm{W}$ & $\mathrm{NC}-\mathrm{E}$ \\
\hline $\mathrm{S}_{1}$ & 2 & 0 & 12 & 4.4 & 60 & 40 \\
\hline $\mathrm{S}_{2}$ & 2 & 0 & 10 & 4.6 & 60 & 42 \\
\hline $\mathrm{S}_{3}$ & 1 & 0 & 10 & 4.4 & 60 & 40 \\
\hline $\mathrm{S}_{4}$ & 0 & 0 & 4 & 3.5 & 80 & 100 \\
\hline
\end{tabular}

Table 4: Summary of the results after the evaluation of strategies.

erativity for both $\mathrm{NC}$. In the case of $\mathrm{NC}-\mathrm{E}$, the operativity for $3-\mathrm{m}$ water depth increases from $60 \%$ to $80 \%$, whereas it rises from $40 \%$ to $100 \%$ for $\mathrm{NC}-\mathrm{W}$. Hence, with the shoal removal the design vessel is able to navigate during the complete period of the simulation. Moreover, vessels with drafts over $6 \mathrm{~m}$ are able to navigate during certain time windows (high water levels at spring tides) of the simulation period. According to these results, $\mathrm{S}_{4}$ was chosen as the most efficient strategy, providing not only a significant improvement in terms of navigational capacity, but also a reduction of morphodynamic changes, thus increasing its life-time. The results of the analysis of the different dredging strategies is summarized in Table 4.

\section{FIGURE 7}

\subsection{Analysis of the shoal removal}

We performed longer morphodynamic simulations to analyze in detail how $\mathrm{S}_{4}$ evolves in terms of operativity. The simulations were also performed for $\mathrm{S}_{1}$ to compare with the unaltered strategy, and spanned a complete year to analyze the influence of the entire range of climate conditions. With the aim 
of performing realistic simulations, the selected period starts on October 1st, 2014, approximately the date for which the bathymetry of $\mathrm{S}_{1}$ was obtained.

Fig. 8 shows the sea levels and wind and wave climates during the simulated period. Between November and March, storms were frequent with maximum wave heights typically over $3 \mathrm{~m}$ (both from the East and West) and wind velocities up to $20 \mathrm{~m} / \mathrm{s}$. However, during spring and summer milder conditions were recorded, with wave heights barely reaching $1.5 \mathrm{~m}$ and predominantly approaching PUI from the Southwest, and wind velocities usually below $10 \mathrm{~m} / \mathrm{s}$.

FIGURE 8

\subsubsection{Morphodynamic evolution}

Fig. 9 a and b show the non-dimensional bed level differences between the initial and final bathymetries for each strategy. A general sedimentation over PUI (approximately $8 \%$ of the initial water depth) is observed, except for the shallow water area located at the East of the river mouth, where erosion is observed. This general sedimentation, which was negligible for the results on section 4.1, agree with the tendency of the inlet to be filled up with sediments described by Reyes-Merlo et al. (2017).

The results in the area where the $\mathrm{NC}$ diverge are clearly different for $\mathrm{S}_{1}$ and $\mathrm{S}_{4}$ : whereas consecutive areas of important sedimentation (up to 40\%) and erosion $(20 \%)$ are obtained for $\mathrm{S}_{1}$, the removal of the shoal reduces significantly the morphodynamic activity of the area, with only sedimentation in the area close to the $\mathrm{NC}-\mathrm{W}$ bend. These differences are also observed in Fig. 9c, where the bathymetry changes along the $\mathrm{NC}$ are depicted: the maximum water depth reduction is decreased from $40 \%\left(\mathrm{~S}_{1}\right)$ to $12 \%\left(\mathrm{~S}_{4}\right)$. 
Furthermore, for the latter the bed level variations are smoothed not only over the shoal, but also upstream the area usually dredged.

\section{FIGURE 9}

\subsubsection{Operativity}

The consequences of these differences on bed level evolution between $\mathrm{S}_{1}$ and $\mathrm{S}_{4}$ were quantified in terms of operativity. Fig. 10 shows the operativity during the complete year for both strategies. A significant increase for both $\mathrm{NC}$ is observed for $\mathrm{S}_{4}$, specially in the case of $\mathrm{NC}-\mathrm{W}$, where the results for $3 \mathrm{~m}$ draft improves from $65 \%$ to $100 \%$. Although these increases were also observed for the 3-month simulations (section 4.1), some differences arise: whereas the operativity for $3 \mathrm{~m}$ draft along NC-E is approximately $80 \%$ after the 3-month simulations, it increases up to $90 \%$ for the complete year. These differences demonstrate that the operativity is not entirely dependent on the initial bathymetry (and hence on the dredging strategy) but also on the local wave climate and the subsequent morphodynamic evolution. This motivates the analysis of the relation between wave climate and morphodynamic evolution performed in section 5.1 .

FIGURE 10

To complete the analysis, the operativity over the entire PUI was also obtained for the complete year considering a draft of $3 \mathrm{~m}$. Fig. 11a shows how the shoal at the PUI mouth significantly reduces the operativity for the unaltered conditions $\left(\mathrm{S}_{1}\right)$, with values slightly over $50 \%$ in some areas. The effects of the shoal removal are evident for the area between the NC Fig. 11b, where the operativity is almost $100 \%$. Fig. 11. depicts the differences between both strategies showing that the operativity improvement is gener- 
alized along the area between the $\mathrm{NC}$, being only reduced in small and very shallow areas at the eastern margin of PUI. In these areas, small variations in water depths results in large reductions in operativity due to the limited initial water depth.

\section{FIGURE 11}

\section{Discussion}

In this section, we use the 1-year simulations for $S_{1}$ and $S_{4}$ to discuss (1) the relation between the drivers and the morphological evolution of the area; (2) the effects of the shoal removal on PUI hydrodynamics and (3) the potential environmental impacts derived from the shoal removal.

\subsection{Relation of tides and wave climate with morphodynamic evolution}

To deepen the understanding of the morphodynamic behavior of PUI, the shoal removal, and the loss of operativity, we analyze the relation between tides and wave climate with the erosion/deposition patterns. Because this kind of analysis is difficult due to the complex interactions between waves, tides, wind and sediment, we tried to isolate the role of waves and tides on the morphodynamic evolution of PUI.

Fig. 12 shows the monthly variations of the water depth along the NC, including their net values and the monthly-averaged wave power vector obtained at PUI mouth. The deposition/erosion values (panels a and c) were obtained as the accumulated mean deposition/erosion rates along the $\mathrm{NC}$ for each month, whereas their net variation is showed in panels b and $d$. The 
wave power vector was obtained as:

$$
\vec{P}=\frac{1}{8} \rho g \vec{H}^{2} c_{g}
$$

where the over-arrow indicates vector, $\rho$ is the water density, $g$ is gravity, $\vec{H}$ is the significant wave height vector averaged in a monthly scale and $c_{g}$ is the group celerity.

Results show that the bed elevation along the NC is closely related with both the intensity and orientation of wave power. Generally, the larger the intensity and the westerly the direction of the wave power, the larger morphodynamics changes along the $\mathrm{NC}$ are found. The wave directionality plays an important role: although the norm of the wave power vector is higher in February, larger morphodynamic variations are found for April and May, which are more westerly oriented. Considering the orientation of the coast, results show that the expected bathymetry changes are more intense for wave power vectors with higher obliquity. The importance of wave directionality on coastal morphodynamics was described in previous studies, such as LópezRuiz et al. (2015), although its importance on navigational channel capacity was not previously addressed. These type of analyses are increasingly relevant, since one of the main impacts of future climate change is expected to be the variation on wave climate directionality (Fernandino et al., 2018), although no reliable information about the local future tendencies are available.

FIGURE 12 


\subsection{Effects on inlet hydrodynamics}

The effects of shoal removal $\left(\mathrm{S}_{4}\right)$ on PUI hydrodynamics were assessed in terms of variations on both tidal flow along the main PUI channel and tidal prism. For the former, tidal ellipses derived from the velocity field at points A, B and C (see Fig. 13a) were analyzed. Fig. 13b-d shows these ellipses for $\mathrm{S}_{1}$ (blue) and $\mathrm{S}_{4}$ (red). Results show that regardless the case, the flow field in these points is almost one-dimensional given the high eccentricity of the ellipses, which are channel-oriented. The increase of the semi-axes indicate that the shoal removal tends to increase up to $50 \%$ the flow velocities not only over the shoal itself, but also along the main PUI channel, although this relative increase is lower upstream. Furthermore, a slight turn of the velocity field is observed at point $\mathrm{C}$, although this change in the direction vanish as we advance into the inner part of PUI.

The tidal prism (Jonge, 1992) was obtained at the PUI mouth for sections DD' and EE' (Fig. 13a). The first is upstream the shoal removal and the cross-sectional area is not affected by the interventions, whereas the latter transect the shoal removal area. Results are shown at Fig. 13 -f where positive values indicate flood. At DD', for $\mathrm{S}_{1}$ during spring (neap) tides the tidal prism ranged between $3.1 \cdot 10^{9} \mathrm{~m}^{3}\left(5.3 \cdot 10^{9} \mathrm{~m}^{3}\right)$ and $-9.4 \cdot 10^{9} \mathrm{~m}^{3}$ $\left(-0.9 \cdot 10^{9} \mathrm{~m}^{3}\right)$, with an averaged value of $-4.5 \cdot 10^{9} \mathrm{~m}^{3}$, indicating that ebb is dominant during the complete year. A strong decrease (up to 80\%) of tidal prism was obtained for $\mathrm{S}_{4}$, for which during spring (neap) tides ranges between $1.3 \cdot 10^{9} \mathrm{~m}^{3}\left(4.8 \cdot 10^{9} \mathrm{~m}^{3}\right)$ and $-2.7 \cdot 10^{9} \mathrm{~m}^{3}\left(-0.6 \cdot 10^{9} \mathrm{~m}^{3}\right)$. The average of tidal prism is $2.3 \cdot 10^{9} \mathrm{~m}^{3}$, what implies that the shoal removal modifies the PUI hydrodynamics to flood-dominant. At EE' the trends are 
very similar, although the absolute values of the tidal prisms are higher. However, in this outer section the tidal prism decrease up to $60 \%$ after the shoal removal, and the flow is ebb-dominant both for $\mathrm{S}_{1}$ and $\mathrm{S}_{4}$.

To deepen the analysis we estimated the impact of the dredging strategies on the overall stability of the PUI mouth following the work by O'Brien (1967), who defined the relation between the tidal prism $(P)$ and the crosssectional area of inlets $(\Omega)$ in (near) equilibrium conditions as:

$$
\Omega=k \cdot P^{\alpha}
$$

where the parameters $k$ and $\alpha$ are coefficients obtained through a regression analysis (D'Alpaos et al., 2009, 2010). Their values in the case of PUI are 4 . $10^{-4}$ and $6 / 7$, respectively. We obtained the equilibrium tidal prism $P=P_{\text {eq }}$ using Eq. 3 and the cross-sectional areas at DD' and EE'. According to O'Brien (1967); Dyer (1995), the navigational capacity of the inlet is more compromised for lower values of $P_{\text {eq. }}$. These equilibrium values were also compared with the averaged tidal prism at each section for $\mathrm{S}_{1}$ and $\mathrm{S}_{4}$ obtained with the numerical model.

Table 5 summarizes the results, showing that the shoal removal increase $P_{\text {eq }}$ at EE' promoting the navigational capacity of PUI, whereas it reduces the differences between the actual tidal prism and its equilibrium values at both DD' and EE'. This is a potential proxy that PUI is closer to its equilibrium reducing its morphodynamic activity (O'Brien, 1967; Blott et al., 2006; Bolla Pittaluga et al., 2015) and highlighting the effectiveness of this nature-based strategy.

FIGURE 13 


\begin{tabular}{ccccc}
\hline Section & \multicolumn{2}{c}{ DD' $^{\prime}$} & \multicolumn{2}{c}{$\mathrm{EE}^{\prime}$} \\
\hline Strategy & $\mathrm{S}_{1}$ & $\mathrm{~S}_{4}$ & $\mathrm{~S}_{1}$ & $\mathrm{~S}_{4}$ \\
\hline$\Omega\left(10^{3} \mathrm{~m}^{2}\right)$ & 8.0 & 8.0 & 12.0 & 20.1 \\
\hline$P_{\text {eq }}\left(10^{8} \mathrm{~m}^{3}\right)$ & 1.0 & 1.0 & 5.3 & 9.0 \\
\hline$|P|\left(10^{8} \mathrm{~m}^{3}\right)$ & 45 & 23 & 125 & 28 \\
\hline
\end{tabular}

Table 5: Equilibrium and actual tidal prism at sections DD' and EE' for $\mathrm{S}_{1}$ and $\mathrm{S}_{4}$.

\subsection{Environmental aspects}

Dredging activities have environmental impacts that affect not only the site itself, but also surrounding areas through a large number of impact vectors (Erftemeijer et al., 2012). Among others consequences, the sediment removal can potentially lead to a temporary decrease in water transparency and increased concentrations of suspended matter and rates of sedimentation (Erftemeijer and Robin Lewis, 2006; Meng et al., 2018). Furthermore, the reduction of the tidal prism can also increase the suspended sediment concentrations (Goodwin, 1987; Dyer, 1995, Anthony, 2004; Zhao et al., 2018). These effects, jointly with an increase in nutrient concentrations and reduced dissolved oxygen in the water column, affect local species reducing the variety and abundance of organism such as benthic species (Lewis et al., 2001; Boyd et al., 2005). These impacts are of major importance in coastal areas, shelf seas and tidal inlets such as PUI, where changes in the ecosystem are also likely to impact most directly on humans (Wakelin et al., 2015).

In the case of PUI, additionally to the increase of turbidity the presence of significant heavy metals concentrations in the sediments increases the environmental impacts of dredging activities in the area. These concentrations 
are due to the proximity of the Ría de Huelva, the mouth of the Tinto and Odiel rivers, which have one of the highest levels of metal pollution of all the rivers of Europe (Usero et al., 2005). Hence, a reduction in the frequency of the maintenance dredging works of the navigational channels would imply a reduction on the environmental risk. As showed throughout the manuscript, the shoal removal represents an efficient alternative to maintain the navigational capacity without further interventions in the short to mid-term. Indeed, results show that the increase on the initial water depths after shoal removal and the reduction of the deposition rates (from approximately $1 \mathrm{~m} / \mathrm{yr}$ for $\mathrm{S}_{0}$ to $0.35 \mathrm{~m} / \mathrm{yr}$ for $\mathrm{S}_{4}$ ) extend the life-time of the intervention from 2-3 years (frequency of the current interventions according to Reyes-Merlo et al. 2017) to more than 8 years. However, the initial dredged volume required for the shoal removal is $50 \%$ above the volume of the dredging works performed historically in the area, implying a period of higher concentrations of contaminants (heavy metals) and turbidity. If these peak concentrations are sustainable for the ecosystems in the area would require a deeper analysis out of the scope of this work.

\section{Conclusions and final remarks}

Despite relevant advances achieved in recent years, sediment transport and siltation problems at tidal inlets are still relevant issues with important impacts on dredging strategies. This work analyses the performance of different dredging alternatives in terms of navigational capacity and operativity in estuarine and tidal inlet environments. Their morphodynamic evolution is also analyzed in detail to evaluate their potential life-times. 
The methodology is based on numerical hydro-morphodynamic simulations, which are applied to Punta Umbría inlet (Southern Spain). This inlet is a highly altered system demanding frequent dredging works to maintain safety water depths. The model was calibrated and tested both for hydrodynamics and morphodynamics and applied to different dredging strategies, including channel deepening, littoral drift barrier and shoal removal. Among these strategies, shoal removal was proven to be the more efficient to improve the navigational channel operativity for different vessel drafts. Given the similarities of the study site with many other worldwide inlets, the conclusions summarized below are of interest for scientists and managers.

After the analysis of the results, the following main conclusions are drawn:

- The numerical model has been successfully calibrated and tested both for the hydro- and morphodynamic modules despite the complexity of the processes involved. An excellent agreement for water levels $(\mathrm{R} \approx$ $0.99)$ and good agreements for East and North velocities $(\mathrm{R} \approx 0.65$ $0.96)$, wave height $(\mathrm{R} \approx 0.7)$ and bottom elevation (MSESS $\approx 0.66$ ) were achieved. These results assured the validity of the performance assessment for the different strategies.

- Among the three strategies proposed to improve the navigational capacity, the shoal removal stands out as the best option after 3-month simulations, since the operativity is increased $20 \%$ and $60 \%$ for eastward and westward navigational channels, respectively. The morphodynamic activity along these channels is significantly reduced, decreasing the deposition rate from approximately $1 \mathrm{~m} / \mathrm{yr}$ to $0.35 \mathrm{~m} / \mathrm{yr}$, thus 
increasing the life-time of the intervention more than a $100 \%$ with respect to the current interventions and reducing the frequency of the dredging works, as suggested by Reyes-Merlo et al. (2017).

- The morphodynamic simulation of the shoal removal strategy during a complete year confirms its excellent performance, which allows the navigation of vessels with deeper drafts. Even considering that this strategy implies an increase of $50 \%$ of the removed sediment volume with respect to the channel deepening, the higher life-time may reduce the environmental impacts as the remobilization of sediments within estuaries has significant implications for water quality and habitat conservation. The minimization of external gradients significantly extends the life-time of the dredging strategies, highlighting that solutions working with nature can significantly improve the sustainable management of altered tidal inlets.

- The analysis of the relation between the morphodynamic evolution of the main navigational channels and the maritime drivers reveals that their sedimentary behavior of tidal inlets with ebb shoals is closely related both with the module and direction of the wave power flux at the mouth of the inlet. In the case of PUI, the higher the module and the westerly the direction are, the higher sedimentation along the channels is observed. This may have significant impacts for climate change scenarios in worldwide inlets.

- The shoal removal slightly modifies the inlet hydrodynamics, increasing the flow velocities and rotating its direction at the mouth of the inlet. 
The averaged tidal prism is reduced, which is a proxy of the inlet tendency of reaching its morphodynamic equilibrium, in accordance with the reduction of the bed level changes over the inlet observed for this strategy.

- Results show that shoal removal is an effective solution for navigable inlets in which periodic dredging works are carried out due to the presence of ebb shoals. The similarity between PUI and many others inlets located United States (Dabees and Kraus, 2008; Buonaiuto and Kraus, 2003) or Europe (Garel et al., 2014, 2015; Garel, 2017) enhance the applicability of the findings described in this work, specifically for scientists and coastal managers dealing with operational, financial and/or environmental issues derived from channel deepening.

\section{Acknowledgments}

This work was partially funded by the European Union through FEDER founding (G-GI3002/IDII), project DRAGAPORT of the Programa Operativo FEDER 2007-2013. We also thank the staff and researchers of the Agency of Public Works of the Andalusia Regional Government for their dedication and professionalism. Miguel A. Reyes-Merlo, Pedro Otíñar and Rafael J. Bergillos are acknowledged for their help during the field campaign and the necessary data. Two anonymous reviewers and Filip Tack (Associate Editor) are also acknowledged for their comments and suggestions which improved significantly the manuscript. 


\section{References}

Álvarez, M., Carballo, R., Ramos, V., Iglesias, G., 2017. An integrated approach for the planning of dredging operations in estuaries. Ocean Engineering 140, 73-83.

Anthony, E.J., 2004. Sediment dynamics and morphological stability of estuarine mangrove swamps in sherbro bay, west africa. Marine Geology 208, $207-224$.

Bales, J.D., Holley, E.R., 1989. Sand transport in Texas tidal inlet. Journal of Waterway, Port, Coastal, and Ocean Engineering 115(4), 427-443.

Barba-Brioso, C., Fernández-Caliani, J., Miras, A., Cornejo, J., Galán, E., 2010. Multi-source water pollution in a highly anthropized wetland system associated with the estuary of Huelva (SW Spain). Marine Pollution Bulletin 60, 1259-1269.

Blott, S.J., Pye, K., Van der Wal, D., Neal, A., 2006. Long-term morphological change and its causes in the Mersey Estuary, NW England. Geomorphology 81, 185-206.

Bolla Pittaluga, M., Tambroni, N., Canestrelli, A., Slingerland, R., Lanzoni, S., Seminara, G., 2015. Where river and tide meet: The morphodynamic equilibrium of alluvial estuaries. Journal of Geophysical Research: Earth Surface 120 (1), 75-94.

Booij, N., Ris, R.C., Holthuijsen, L.H., 1999. A third-generation wave model for coastal regions: 1. Model description and validation. Journal of Geophysical Research: Oceans 104 (C4), 7649. 
Bosboom, J., Reniers, A.J.H.M., Luijendijk, A.P., 2014. On the perception of morphodynamic model skill. Coastal Engineering 94, 112-125.

Boyd, S.E., Limpenny, D.S., Rees, H.L., Cooper, K.M., 2005. The effects of marine sand and gravel extraction on the macrobenthos at a commercial dredging site (results 6 years post-dredging). ICES Journal of Marine Science 62, 145-162.

Brown, B., Le Tissier, M., Scoffin, T., Tudhope, A., 1990. Evaluation of the environmental impact of dredging on intertidal coral reefs at Ko Phuket, Thailand, using ecological and physiological parameters. Marine Ecology Progress Series, 273-281.

Buonaiuto, F.S., Kraus, N.C., 2003. Limiting slopes and depths at ebb-tidal shoals. Coastal Engineering 48, 51-65.

CEDEX, 2013. Estudio de la dinámica litoral, defensa y propuesta de mejora en las playas con problemas: Estudio de actuación del tramo de costa comprendido entre las desembocaduras de los ríos Guadiana y Guadalquivir. Technical Report (in Spanish). Centro de Estudio y Experimentación de Obras Públicas, Gobierno de España.

Cheng, R.T., Casulli, V., Gartner, J.W., 1993. Tidal, residual, intertidal mudflat (TRIM) model and its applications to San Francisco Bay, California. Estuarine, Coastal and Shelf Science 36, 235-280.

Dabees, M., Kraus, N., 2008. Cumulative effects of channel and ebb shoal dredging on inlet evolution in southwest Florida, USA. In: Proceedings 
of the 31st International Conference on Coastal Engineering, Hamburg, Germany, , 2303-2315.

D'Alpaos, A., Lanzoni, S., Marani, M., Rinaldo, A., 2009. On the O'Brien-Jarrett-Marchi law. Rendiconti Lincei 20, 225-236.

D'Alpaos, A., Lanzoni, S., Marani, M., Rinaldo, A., 2010. On the tidal prism-channel area relations. Journal of Geophysical Research: Earth Surface 115(F1).

Davis, R., Fitzgerald, D., 2004. Beaches and coasts. Oxford: Blackwell. 419 pp 300.

Dias, J., Lopes, J., 2006a. Calibration and validation of hydrodynamic, salt and heat transport models for Ría de Aveiro lagoon (Portugal). Journal of Coastal Research , 1680-1684.

Dias, J.M., Lopes, J., 2006b. Implementation and assessment of hydrodynamic, salt and heat transport models: the case of Ría de Aveiro Lagoon (Portugal). Environmental Modelling \& Software 21, 1-15.

Dias, J.M., Sousa, M., Bertin, X., Fortunato, A., Oliveira, A., 2009. Numerical modeling of the impact of the Ancão Inlet relocation (Ría Formosa, Portugal). Environmental Modelling \& Software 24, 711-725.

Dissanayake, P., Wurpts, A., 2013. Modelling an anthropogenic of a tidal basin evolution applying tidal and wave boundary forcings: Ley Bay, East Frisian Wadde Sea. Coastal Engineering 82, 9-24. 
Duong, T.M., Ranasinghe, R., Walstra, D., Roelvink, D., 2016. Assessing climate change impacts on the stability of small tidal inlet systems: Why and how? Earth-science reviews 154, 369-380.

Dyer, K.R., 1995. Sediment transport processes in estuaries. volume 53, pp. 423-449. Elsevier.

Eelkema, M., Wang, Z., Stive, M., 2012. Impact of Back-Barrier Dams on the Development of the Ebb-Tidal Delta of the Eastern Scheldt. Journal of Coastal Research 285, 1591-1605.

Egbert, G., Erofeeca, S., 2002. Efficient inverse modeling og barotroptic ocean tides. Journal of Atmosphere Ocean Tech. 19, 183-204.

Elias, E., Hansen, J., 2012. Understanding processes controlling sediment transports at the mouth of a highly energetic inlet system (San Francisco Bay, CA). Marine Geology 345, 207-221.

Erftemeijer, P., Riegl, B., Hoeksema, B., Todd, P., 2012. Environmental impacts of dredging and other sediment disturbances on corals: a review. Marine Pollution Bulletin 64, 1737-1765.

Erftemeijer, P.L., Robin Lewis, R.R., 2006. Environmental impacts of dredging on seagrasses: A review. Marine Pollution Bulletin 52, 1553-1572.

Fernandino, G., Elliff, C.I., Silva, I.R., 2018. Ecosystem-based management of coastal zones in face of climate change impacts: Challenges and inequalities. Journal of Environmental Management 215, 32-39. 
Fortunato, A.B., Nahon, A., Dodet, G., Pires, A.R., Freitas, M.C., Bruneau, N., Azevedo, A., Bertin, X., Benevides, P., Andrade, C., Oliveira, A., 2014. Morphlogical evolution of an ephermeral tidal inlet from opening to closure: The Albufeira inlet, Portugal. Continental Shelf Research 73, 49-63.

Garel, E., 2017. Efficient dredging strategy for channel maintenance of the Guadiana ebb-delta, in: Proc. of Coastal Dynamics 2017, Helsingor, Denmark.

Garel, E., Sousa, C., Ferreira, 2015. Sand bypass and updrift beach evolution after jetty construction at an ebb-tidal delta. Estuarine, Coastal and Shelf Science 167, 4-13.

Garel, E., Sousa, C., Ferreira, Ó., Morales, J.A., 2014. Decadal morphological response of an ebb-tidal delta and down-drift beach to artificial breaching and inlet stabilisation. Geomorphology 216, 13-25.

Geyer, W., Trowbridge, H., Bowen, M., 2000. The Dynamics of a Partially Mixed Estuary. Physical Oceanography 30, 2035-2048.

Goodwin, C.R., 1987. Tidal-flow, circulation, and flushing changes caused by dredge and fill in Tampa Bay, Florida. Technical Report. Dept. of the Interior, U.S. Geological Survey,.

Hansen, J., Elias, E., List, J., Erikson, L., Barnard, P., 2013. Tidally influenced alongshore circulation at an inlet-adjacent shoreline. Continental Shelf Research 56, 26-38. 
Harff, J., Graf, G., Bobertz, B., 2009. Dynamics of natural and anthropogenic sedimentation (dynas). Journal of Marine Systems 75, 315-316.

Hinwood, J., McLean, E., 2018. Tidal inlets and estuaries: Comparison of Bruun, Escoffier, O'Brien and attractors. Coastal Engineering 133, 92-105.

I.E.O., 1992. (Instituto Español de Ocenaografría) Variación espaciotemporal de parámetros físico-químicos y biológicos en la Ría de Huelva y área de influencia, en el período 1987-1991 (in Spanish). Internal report no 138:103.

Iglesias, G., Carballo, R., 2009. Seasonality of the circulation in the Ría de Muros (NW Spain). Journal of Marine Systems 78, 94-108.

Iglesias, G., Sánchez, M., Carballo, R., Fernández, H., 2012. The TSE index e A new tool for selecting tidal stream sites in depth-limited regions. Renewable Energy 48, 350-357.

Je, C.H., Hayes, D.F., Kim, K.S., 2007. Simulation of resuspended sediments resulting from dredging operations by a numerical flocculent transport model. Chemosphere 70(2), 187-195.

Jonge, V.N.D., 1992. Tidal flow and residual flow in the Ems Estuary. Estuarine, Coastal and Shelf Science 34, 1-22.

Knowles, N., Cayan, D.R., 2004. Elevational dependence of projected hydrologic changes in the San Francisco estuary and watershed. Climatic Change 62, 319-336. 
Kraus, N.C., 2000. Reservoir model of ebb-tidal shoal evolution and sand bypassing. Journal of Waterway, Port, Coastal, and Ocean Engineering 126, 305-313.

Lesser, G., Roelvink, J., Van Kester, J., Stelling, G., 2004. Development and validation of a three-dimensional morphological model. Coastal Engineering 51, 883-915.

Lewis, M.A., Weber, D.E., Stanley, R.S., Moore, J.C., 2001. Dredging impact on an urbanized Florida bayou: Effects on benthos and algal-periphyton. Environmental Pollution 115, 161-171.

López-Ruiz, A., Solari, S., Ortega-Sánchez, M., Losada, M., 2015. A simple approximation for wave refraction-application to the assessment of the nearshore wave directionality. Ocean Modelling 96, 324-333.

Luijendijk, A.P., Ranasinghe, R., de Schipper, M.A., Huisman, B.A., Swinkels, C.M., Walstra, D.J., Stive, M.J., 2017. he initial morphological response of the Sand Engine: A process-based modelling study. Coastal Engineering 119, 1-14.

Meng, X., Jiang, X., Li, Z., Wang, J., Cooper, K.M., Xie, Z., 2018. Responses of macroinvertebrates and local environment to short-term commercial sand dredging practices in a flood-plain lake. Science of the Total Environment 631-632, 1350-1359.

Militello, A., Kraus, N.C., 2001. Re-alignment of an inlet entrance channel by ebb-tidal eddies, in: Coastal Dynamics'01, pp. 423-432. 
Montero, N., Belzunce-Segarra, M.J., Del Campo, A., Garmendia, J.M., Ferrer, L., Larreta, J., González, M., Maidana, M.A., Espino, M., 2013. Integrative environmental assessment of the impact of Pasaia harbour activities on the Oiartzun estuary (southeastern Bay of Biscay). Journal of Marine Systems 109-110, S252-S260.

Morales, J.A., Borrego, J., Davis, R.A., 2014. A new mechanism for chenier development and a facies model of the Salts Island chenier plain (SW Spain). Geomorphology 204, 265-276.

Muñoz, F.R., González-Regalado, M., Flores, J.B., Morales, J., 1997. The response of ostracod assemblages to recent pollution and sedimentary processes in the Huelva Estuary, SW Spain. Science of the Total Environment 207, 91-103.

Murphy, A., 1988. Skill scores based on the mean square error and their relationships to the correlation coefficient. Monthly Weather Review 116, $2417-2424$.

Nienhuis, J.H., Ashton, A.D., Nardin, W., Fagherazzi, S., Giosan, L., 2016. Alongshore sediment bypassing as a control on river mouth morphodynamics. Journal of Geophysical Research: Earth Surface 121, 664-683.

Oberle, F.K., Storlazzi, C.D., Hanebuth, T.J., 2014. Wave-driven sediment mobilization on a storm-controlled continental shelf (northwest iberia). Journal of Marine Systems 139, 362-372.

O'Brien, M.P., 1967. Equilibrium flow areas of tidal inlets on sandy coasts. Coastal Engineering 1966 , 676-686. 
Ray, R.D., 2001. Inversion of oceanic tidal currents from measured elevations. Journal of Marine Systems 28, 1-18.

Reniers, A.J., Roelvink, J., Thornton, E., 2004. Morphodynamic modeling of an embayed beach under wave group forcing. Journal of Geophysical Research: Oceans 109(C1).

Reyes-Merlo, M. Á. Tintoré-Parra, A., Díez-Minguito, M. andOrtegaSánchez, M., Losada, M.A., 2015. Morphodynamic evolution and influence of dredging activities in small-scale mesotidal estuaries: the case of Punta Umbría (Southwestern Spain). In Proceedings of the 36th IAHRInternational Association for Hydro-Environment Engineering and Research World Congress 100.

Reyes-Merlo, M.A., Ortega-Sánchez, M., Díez-Minguito, M., Losada, M.A., 2017. Efficient dredging strategy in a tidal inlet based on an energetic approach. Ocean and Coastal Management 146, 157-169.

Ris, R.C., Holthuijsen, L.H., Booij, N., 1999. A third-generation wave model for coastal regions: 2. Verification. Journal of Geophysical Research: Oceans 104(C4), 7667.

Rodríguez-Ramírez, A., 2008. The impact of man on the morphodynamics of the Huelva coast (SW Spain)/Efectos antrópicos en la morfodinámica de la costa de Huelva (SO España). Journal of Iberian Geology 34, 313-327.

Roman, C.T., Peck, J.A., Allen, J., King, J.W., Appleby, P.G., 1997. Accretion of a New England (USA) salt marsh in response to inlet migration, 
storms, and sea-level rise. Estuarine, Coastal and Shelf Science 45, 717727.

Ruggiero, P., Walstra, D., Gelfenbaum, G., Van Ormondt, M., 2009. Seasonal-scale nearshore morphological evolution: Field observations and numerical modeling. Coastal Engineering 56, 1153-1172.

Ruiz, F., González-Regalado, M., Muñoz, J., Abad, M., Toscano, A., Prudencio, M., Dias, M., 2014. Distribution of heavy metals and pollution pathways in a shallow marine shelf: assessment for a future management. International Journal of Environmental Science and Technology 11, 1249 1258.

Sainz, A., Grande, J., De la Torre, M., 2004. Characterisation of heavy metal discharge into the Ría of Huelva. Environment International 30, 557-566.

Sainz, A., Ruiz, F., 2006. Influence of the very polluted inputs of the TintoOdiel system on the adjacent littoral sediments of southwestern Spain: a statistical approach. Chemosphere 62, 1612-1622.

Seminack, C.T., McBride, R.A., 2018. A life-cycle model for wave-dominated tidal inlets along passive margin coasts of North Admerica. Geomorphology $304,141-158$.

Smith, S.D., Anderson, R.J., Oost, W.A., Kraan, C., Maat, N., De Cosmo, J., Katsaros, K.B., Davidson, K.L., Bumke, K., Hasse, L., et al., 1992. Sea surface wind stress and drag coefficients: The HEXOS results. BoundaryLayer Meteorology 60, 109-142. 
Usero, J., Morillo, J., Gracia, I., 2005. Heavy metal concentrations in molluscs from the Atlantic coast of southern Spain. Chemosphere 59, 11751181.

Van Leeuwen, S., Van der Vegt, M., Swart, H., 2003. Morphodynamics of ebb-tidal deltas: a model approach. Estuarine, Coastal and Shelf Science $57,1-9$.

Van Maren, D., Van Kessel, T., Cronin, K., Sittoni, L., 2015. The impact of channel deepening and dredging on estuarine sediment concentration. Continental Shelf Research 95, 1-14.

Van Rijn, L., 1993. Principles of Sediment Transport in Rivers, Estuaries and Coastal Seas. Aqua Publications, Amsterdam, Netherlands.

Van Rijn, L.C., 2007. Unified view of sediment transport by currents and waves. I: Initiation of motion, bed roughness, and bed-load transport. Journal of Hydraulic Engineering 133, 649-667.

Varriale, A.C., Crema, R., Galletti, M.C., Zunarelli, R.V., et al., 1985. Environmental impact of extensive dredging in a coastal marine area. Marine Pollution Bulletin 16, 483-488.

Vikas, M., Reddy, N.A., Rao, S., Seelam, J.K., 2015. Classification of tidal inlets along the central west coast of India. Procedia Engineering 116, $912-921$.

Wakelin, S.L., Artioli, Y., Butenschön, M., Allen, J.I., Holt, J.T., 2015. Modelling the combined impacts of climate change and direct anthropogenic 
drivers on the ecosystem of the northwest European continental shelf. Journal of Marine Systems 152, 51-63.

Wang, Y., Tang, L., Wang, C., Liu, C., Dong, Z., 2014a. Combined effects of channel dredging, land reclamation and long-range jetties upon the longterm evolution of channel-shoal system in Qinzhou bay, SW China. Ocean Engineering 91, 340-349.

Wang, Y., Tang, L., Wang, C., Liu, C., Z.D., D., 2014b. Combined effects of channel dredging, land reclamation and long-range jetties upon the longterm evolution of channel-shoal system in Qinzhou bay, SW China. Ocean Engineering 91, 340-349.

Wilber, D.H., Clarke, D.G., 2001. Biological effects of suspended sediments: a review of suspended sediment impacts on fish and shellfish with relation to dredging activities in estuaries. North American Journal of Fisheries Management 21, 855-875.

Zarzuelo, C., Díez-Minguito, M., Ortega-Sánchez, M., López-Ruiz, A., Losada, M., 2015. Hydrodynamics and response to planned human interventions in a highly altered embayment: The example of the Bay of Cádiz (Spain). Estuarine, Coastal and Shelf Science 167, 75-85.

Zarzuelo, C., López-Ruiz, A., Alpaos, A.D., Carniello, L., Ortega-Sánchez, M., 2018. Assessing the morphodynamic response of human-altered tidal embayments. Geomorphology 320, 127-141.

Zarzuelo, C., López-Ruiz, A., Díez-Minguito, M., Ortega-Sánchez, M., 2017. 
957

Tidal and subtidal processes in a constricted bay: observations and modelling. Estuarine, Coastal and Shelf Science 185, 55-68.

Zhao, J., Guo, L., He, Q., Wang, Z.B., van Maren, D., Wang, X., 2018. An analysis on half century morphological changes in the changjiang estuary: Spatial variability under natural processes and human intervention. Journal of Marine Systems 181, 25-36. 


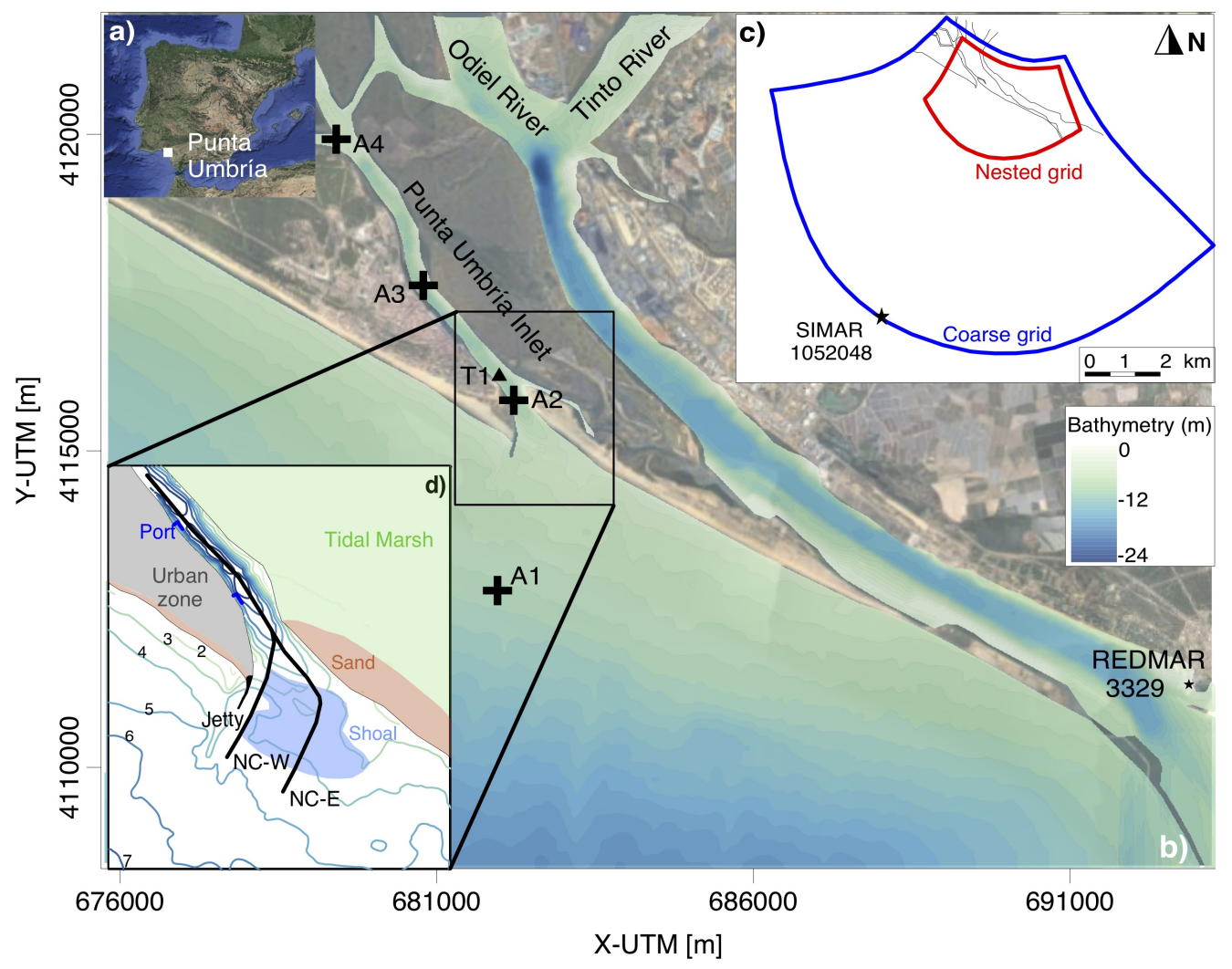

Figure 1: a) Location of the study site (Punta Umbría inlet, PUI, southwestern Spain). b) PUI bathymetry and location of the field survey instruments: ADCP (A) and tidal gauge (T). c) Grids of the numerical model and location of the wave and wind data used (SIMAR 1054048). d) Schematic description of PUI, including the navigational channels used in the area (NC-W and NC-E). 

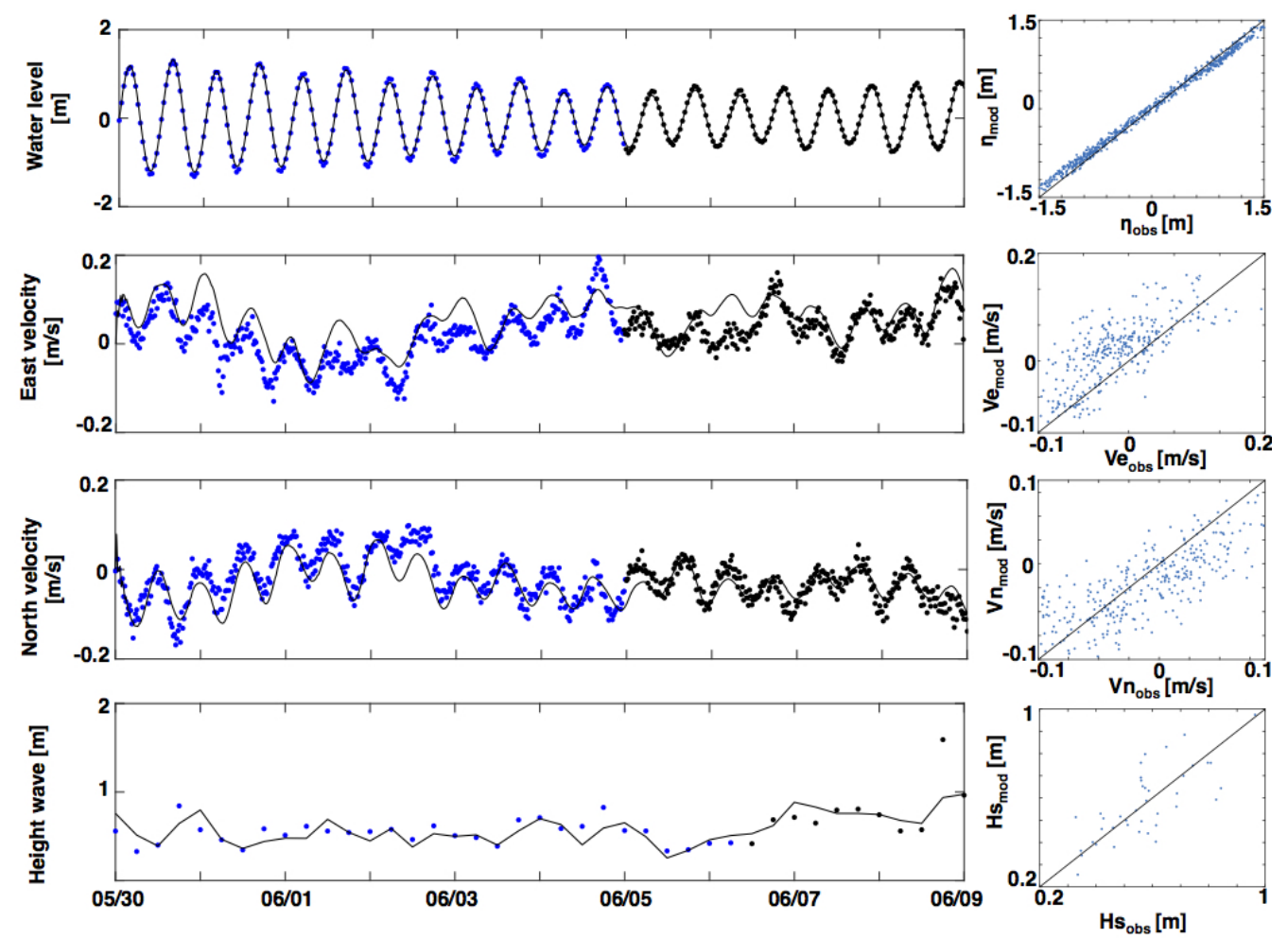

Figure 2: From upper to lower left panels: water level, north velocity, east velocity and wave height at $A_{1}$ (Fig. 1). Black and blue points correspond to observations for the calibration and testing periods, respectively, whereas the black line corresponds to modeled data. Right panels represent the linear regression between observations and model results. 

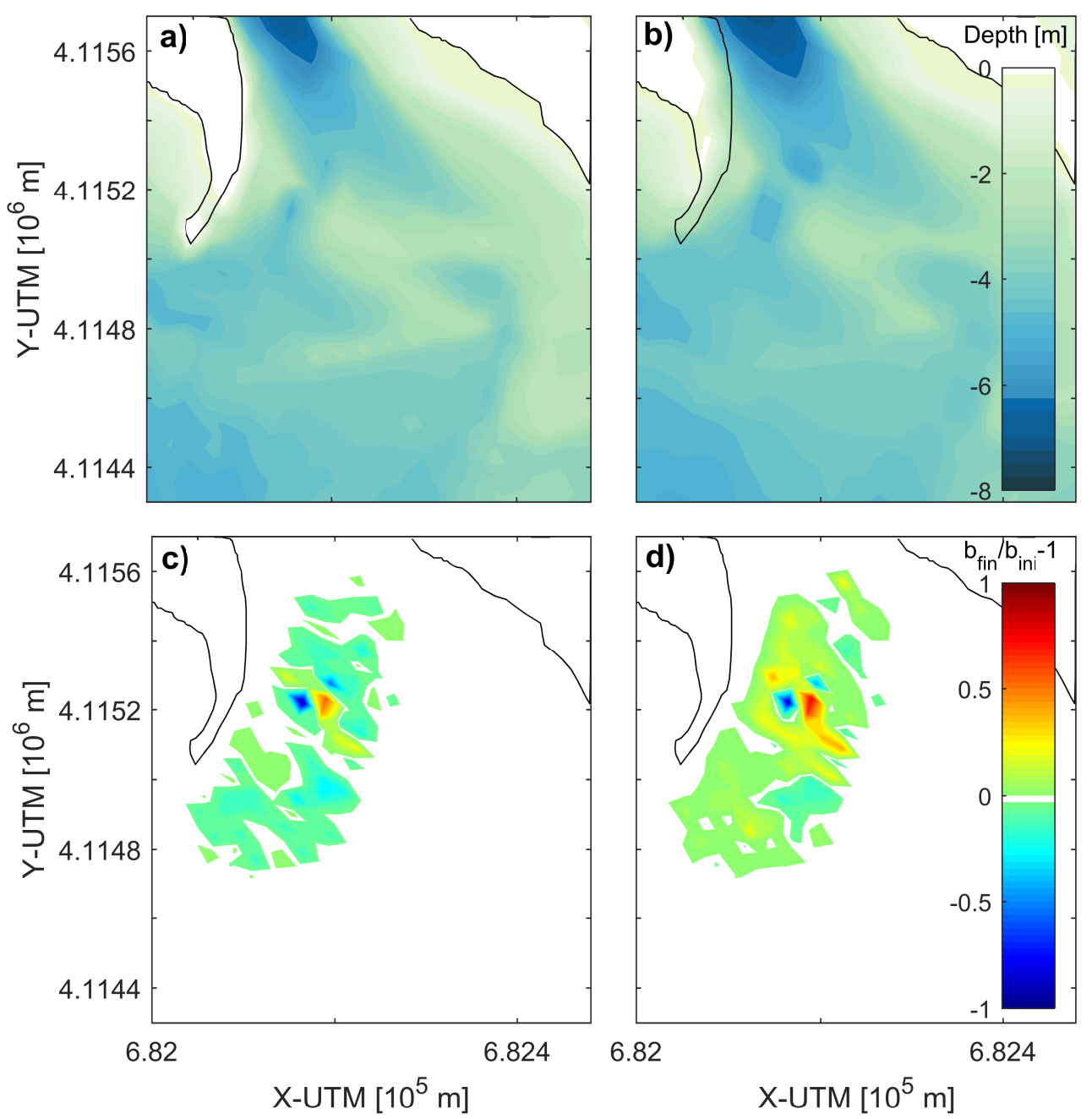

Figure 3: Bottom elevation observed (a) and computed (b) and differences of the bottom elevation between the initial and final steps of the simulation for the measured (c) and modeled (d) data. Red and blue colors indicate erosion and sedimentation, respectively. 

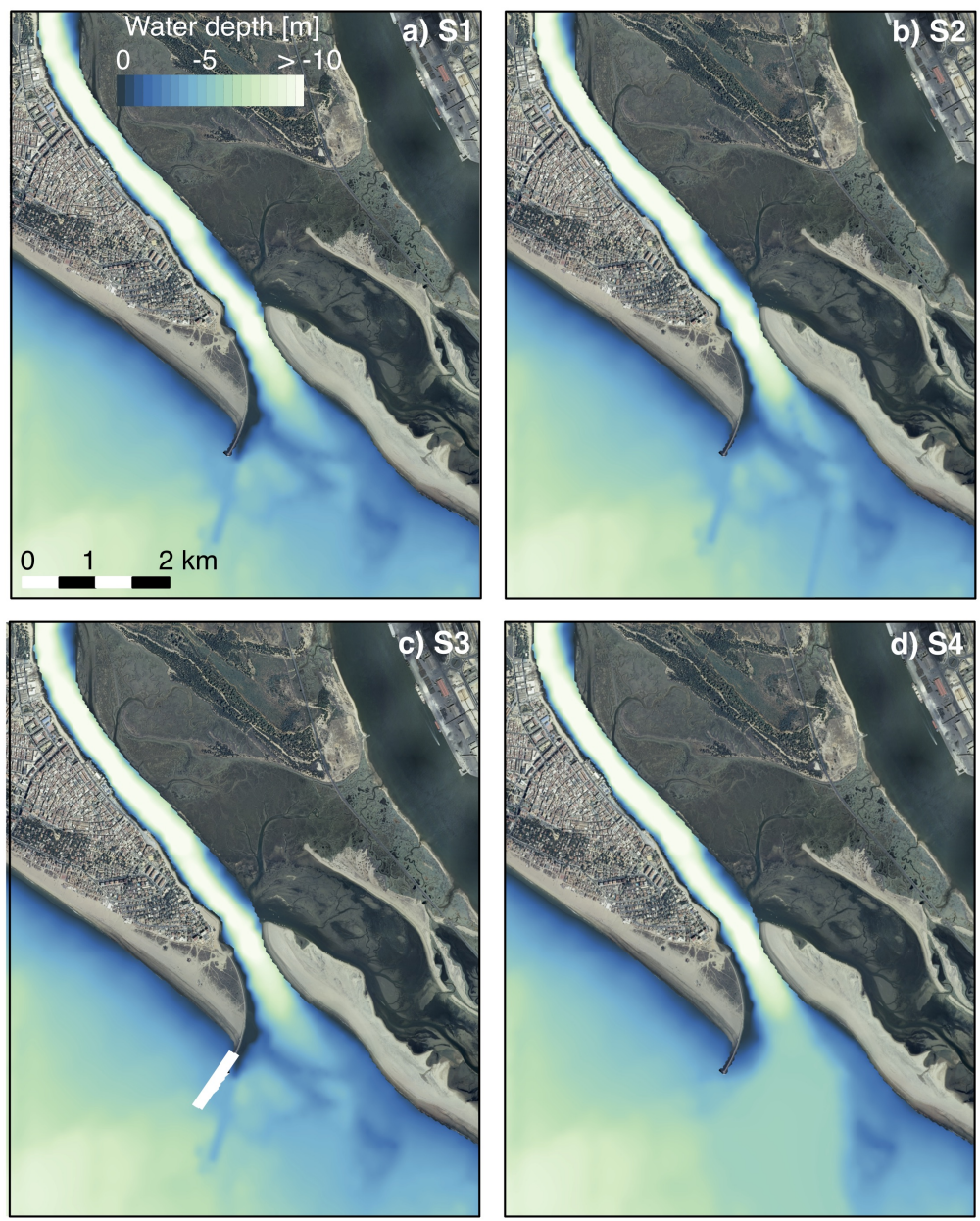

Figure 4: Strategies tested: a) $\mathrm{S}_{1}$, initial configuration of PUI, $\mathrm{b} \mathrm{S}_{2}$, channel deepening, c) $\mathrm{S}_{3}$, littoral drift barrier and d) $\mathrm{S}_{4}$, shoal removal. 

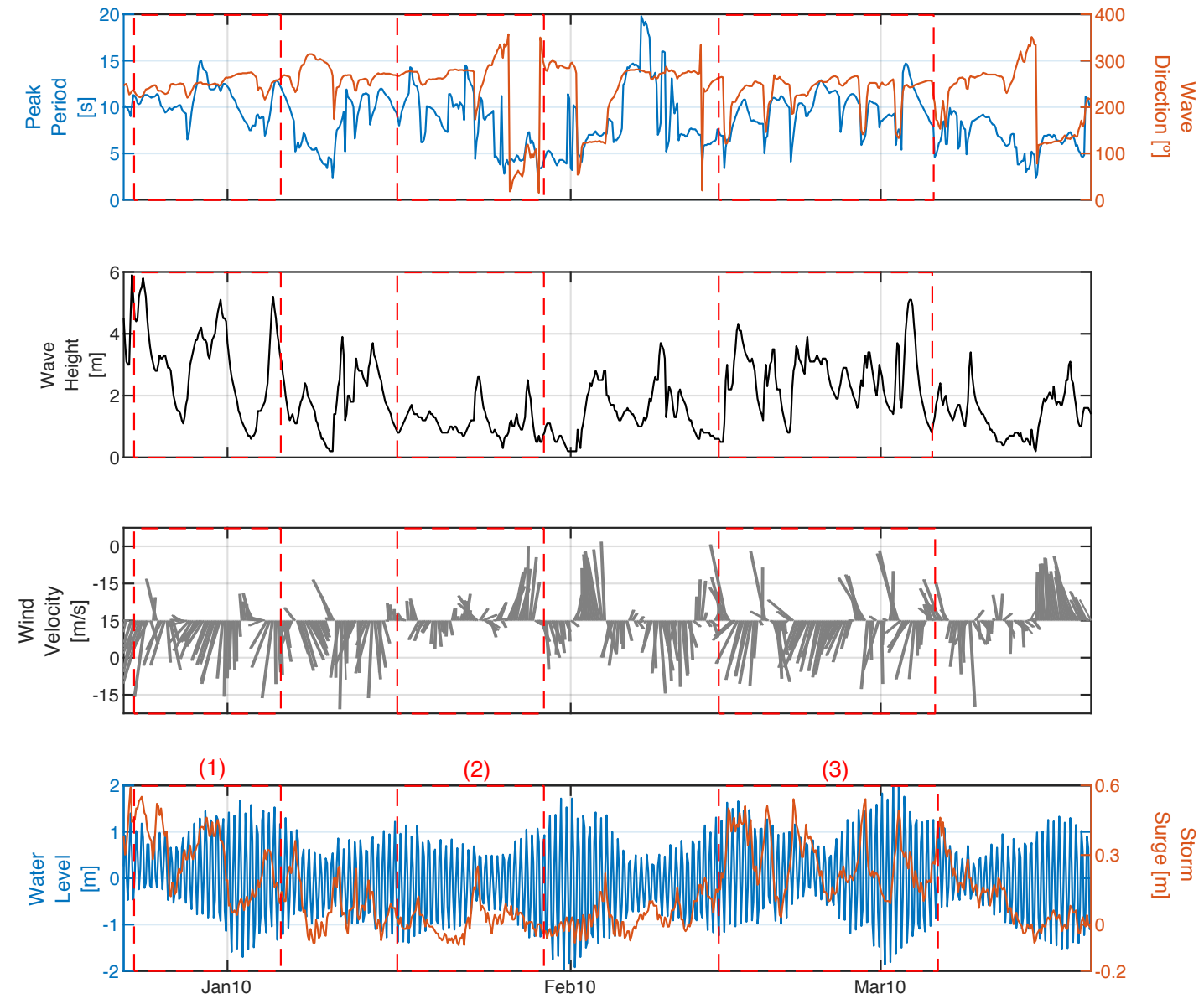

Figure 5: From top to bottom: Panel 1 shows the peak period and wave direction at SIMAR 1052048 in blue and red lines, respectively (Fig. 1). Panels 2 and 3 represent the wave height and wind velocities measured off the coast at SIMAR 1052048 (Fig. 1). Panel 4 represents the water level and the storm surge measured at REDMAR 3329 (Fig. 1) in blue and red line, respectively. The red dashed boxes indicate three different phases in terms of wave climate identified: (1) sequence of storms, (2) milder wave energy conditions, and (3) consistent storm conditions. 

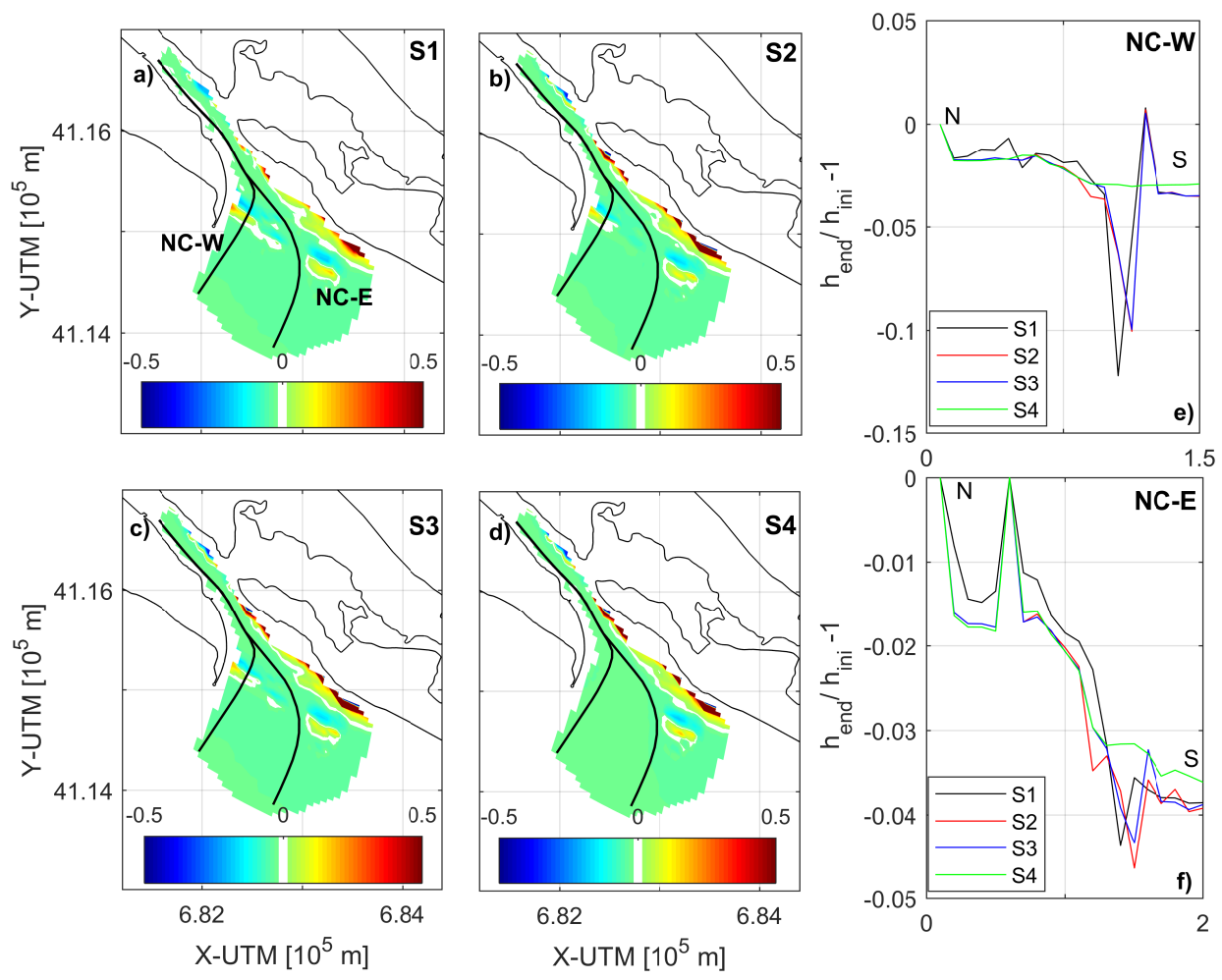

Figure 6: Non-dimensional bed level differences between the initial and the end of the simulations (blue = sedimentation): (a) $\mathrm{S}_{1}$, (b) $\mathrm{S}_{2}$, (c) $\mathrm{S}_{3}$ and (d) $\mathrm{S}_{4}$. The third column represents the differences of water depth between the end and the beginning of the simulation for $\mathrm{NC}-\mathrm{W}$ (e) and $\mathrm{NC}-\mathrm{E}$ (f). Negative values represent sedimentation. The NC are marked with solid lines in panels a-d. 

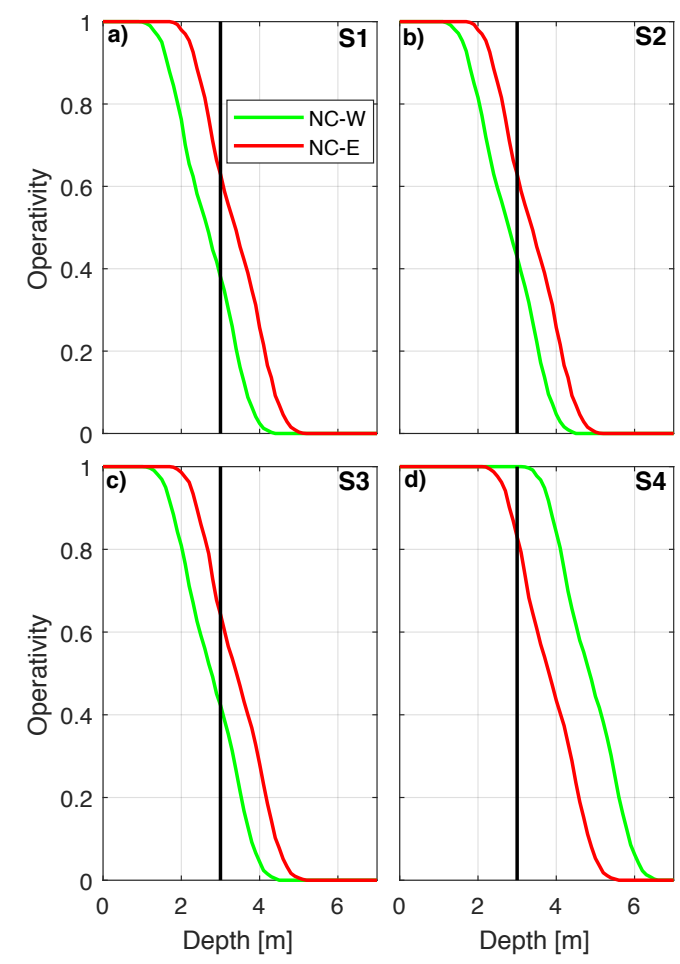

Figure 7: Operativity (non-dimensional ratio of navigable hours per year) for each NC for $\mathrm{S}_{1}$ (a) to $\mathrm{S}_{4}(\mathrm{~d})$. The $\mathrm{NC}$ are plotted in panel e. 

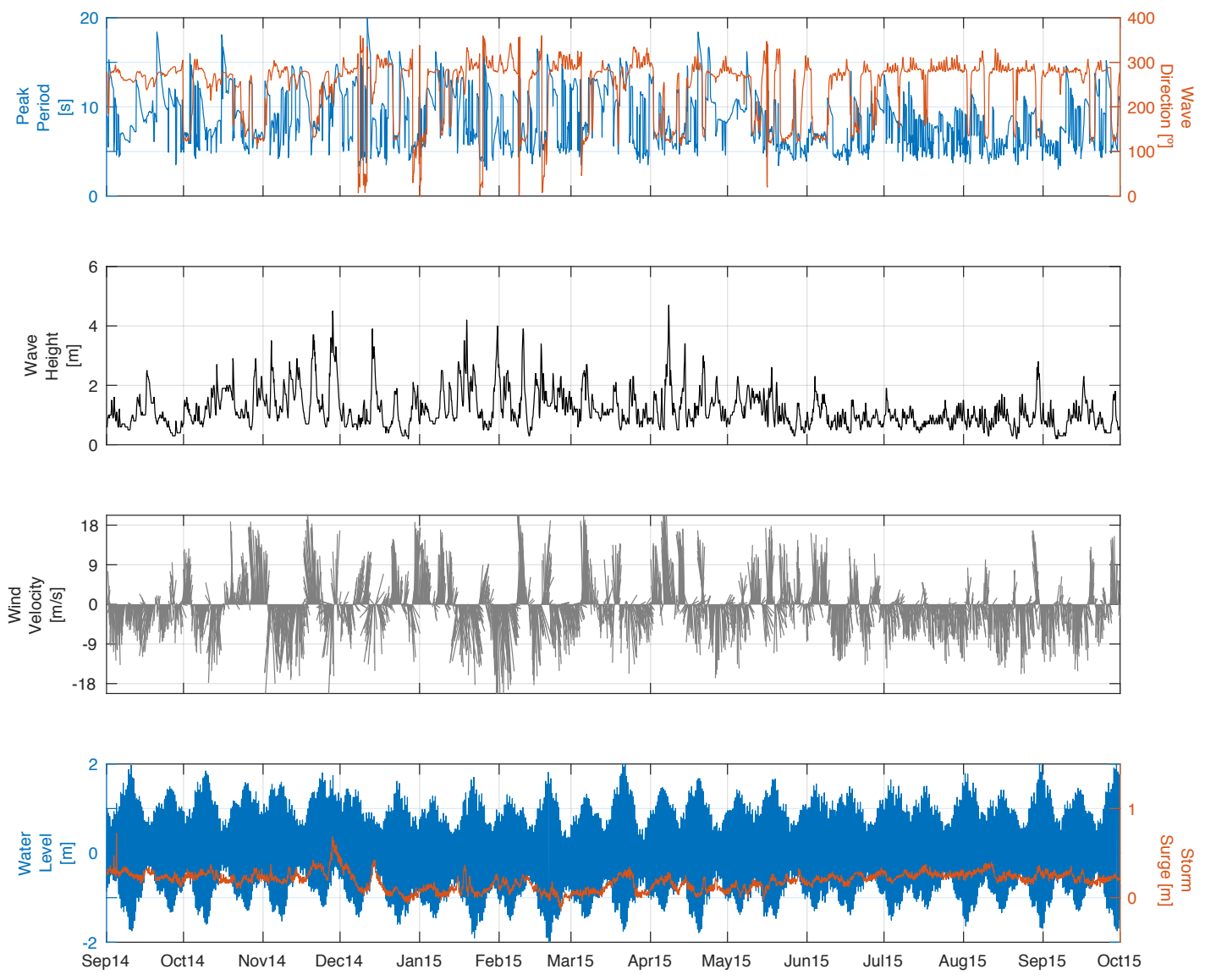

Figure 8: From top to bottom: Panel 1: Peak period and wave direction (SIMAR 1052048, Fig. (1) are represented in blue and red line, respectively. Panels 2 and 3 show, respectively, the wave height and wind velocities (SIMAR 1052048, Fig. 1). Panel 4 represents the water level and the storm surge measured at REDMAR 3329 (Fig. 1) in blue and red line, respectively. 

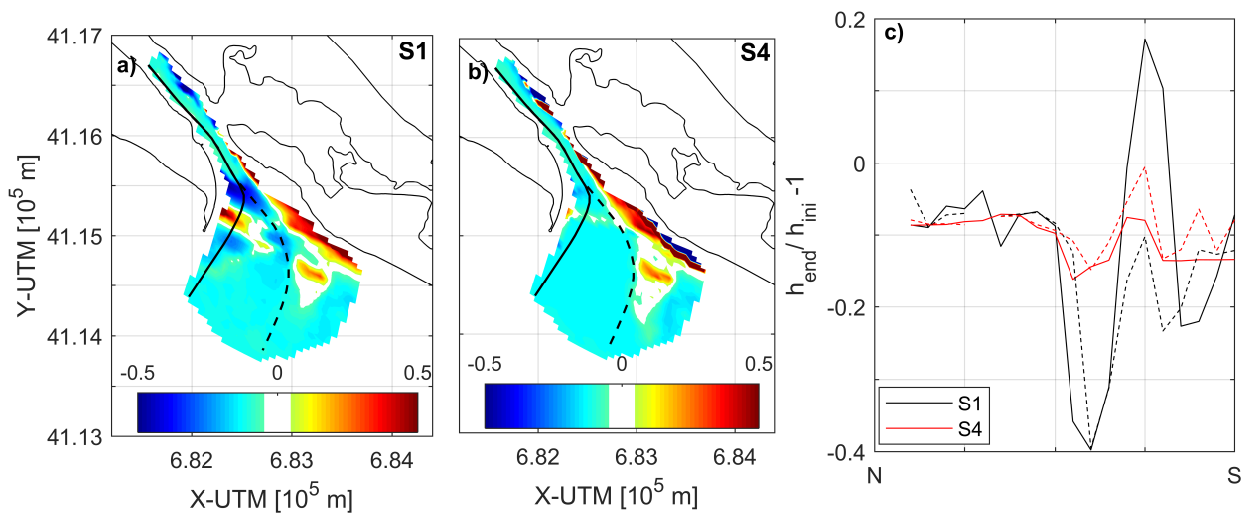

Figure 9: Non-dimensional bed level differences between initial and final bathymetries of PUI (blue colors indicate sedimentation): a) $\mathrm{S}_{1}$, b) $\mathrm{S}_{2}$ and c) results along $\mathrm{NC}-\mathrm{W}$ (solid line) and NC-E (dashed line). The NC are marked with solid lines in panels a and b. 


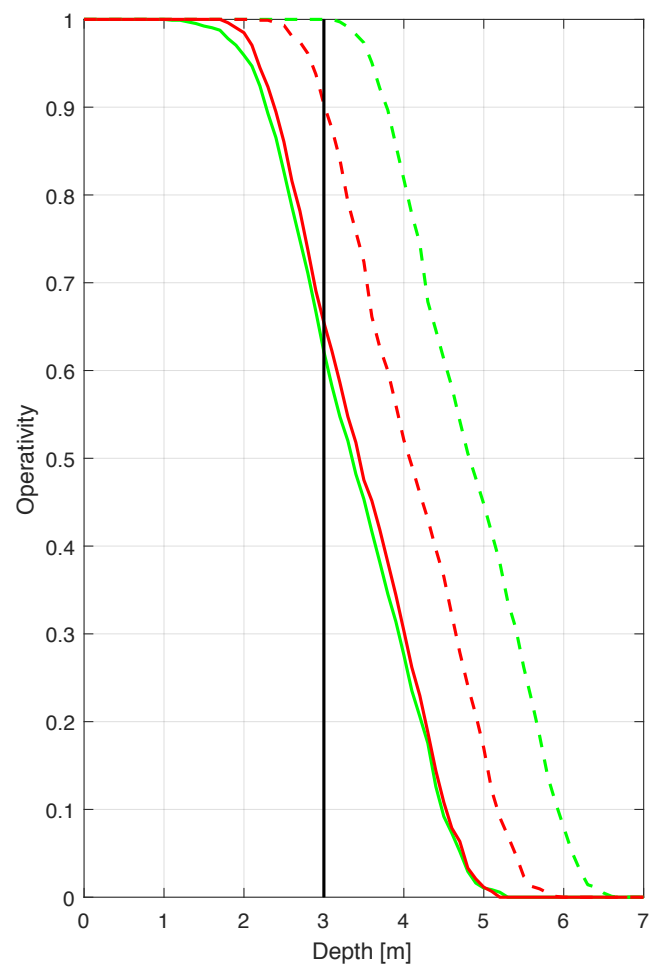

Figure 10: Operativity along $\mathrm{NC}-\mathrm{W}$ (green) and $\mathrm{NC}-\mathrm{E}$ (red) for $\mathrm{S}_{1}$ and $\mathrm{S}_{4}$ (solid and dashed lines, respectively). The inset represents the location of NC and initial bathymetry of $\mathrm{S}_{1}$. 

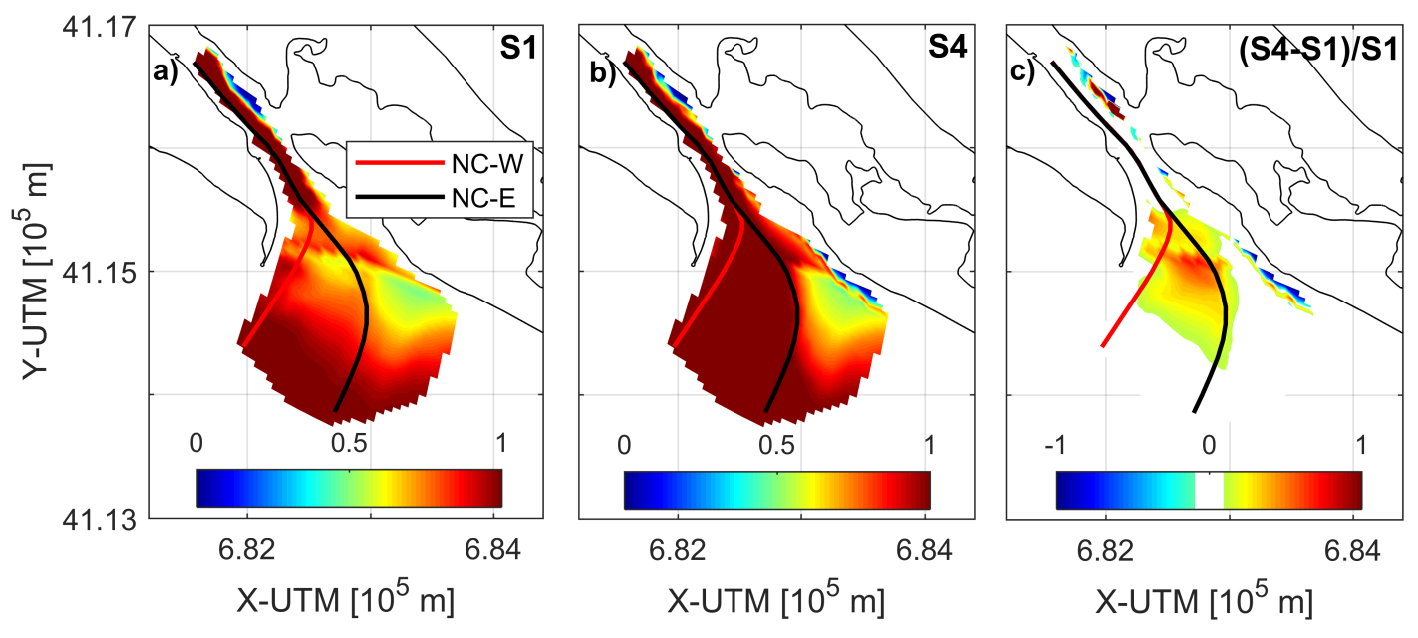

Figure 11: Operativity over PUI for a $3 \mathrm{~m}$ draft vessel: a) $\mathrm{S}_{1}$, b) $\mathrm{S}_{4}$ and c) non-dimensional differences between $\mathrm{S}_{1}$ and $\mathrm{S}_{4}$. 

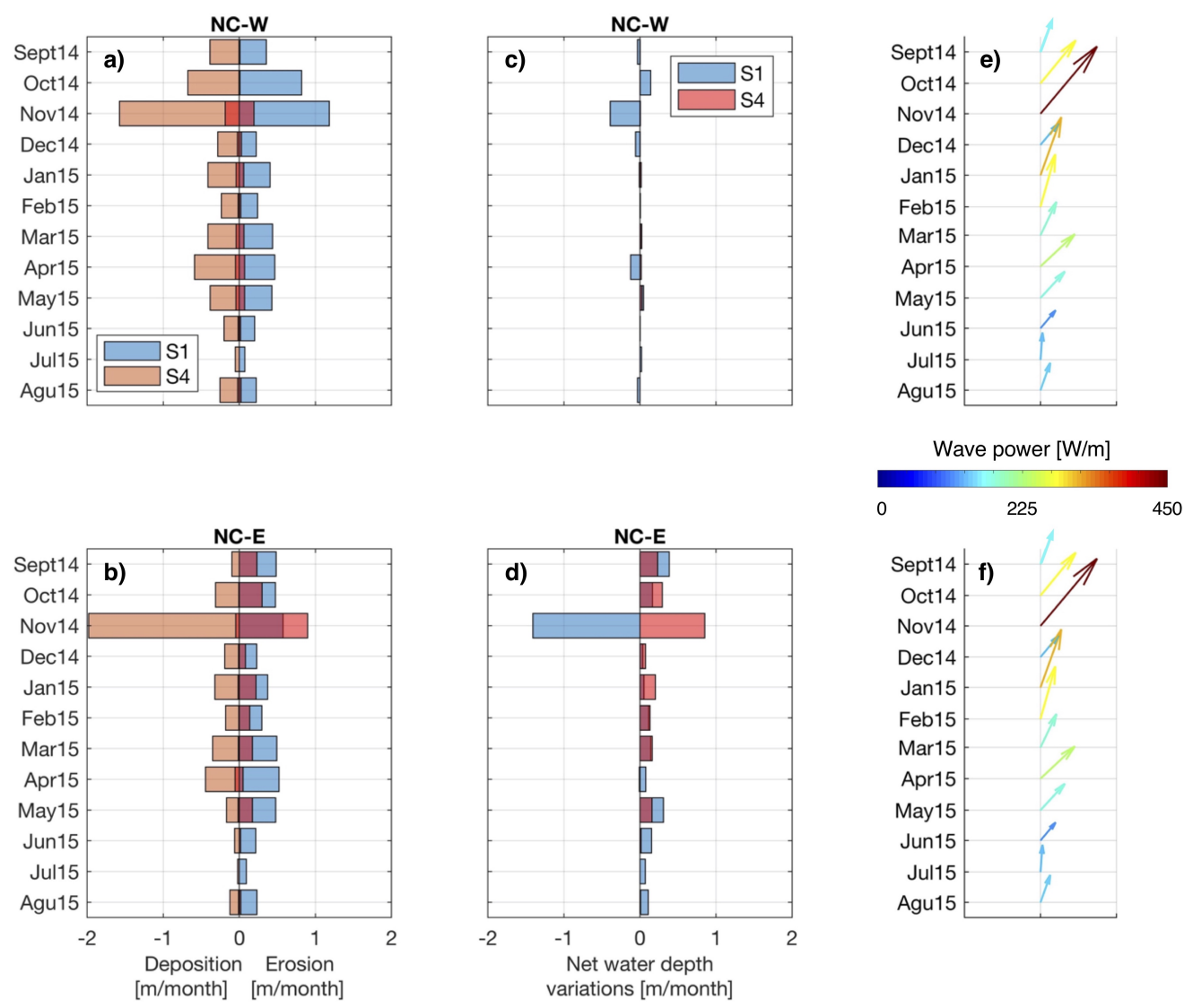

Figure 12: Monthly variations in cumulative sedimentation/erosion along the NC and monthly-averaged wave power vector at the PUI mouth. Panels a and c (b-d) depicts the cumulative mean deposition/erosion and the net water depth changes along $\mathrm{NC}-\mathrm{W}$ (NC-E) on a monthly basis. Panels e and f show the wave power vector for each month. 


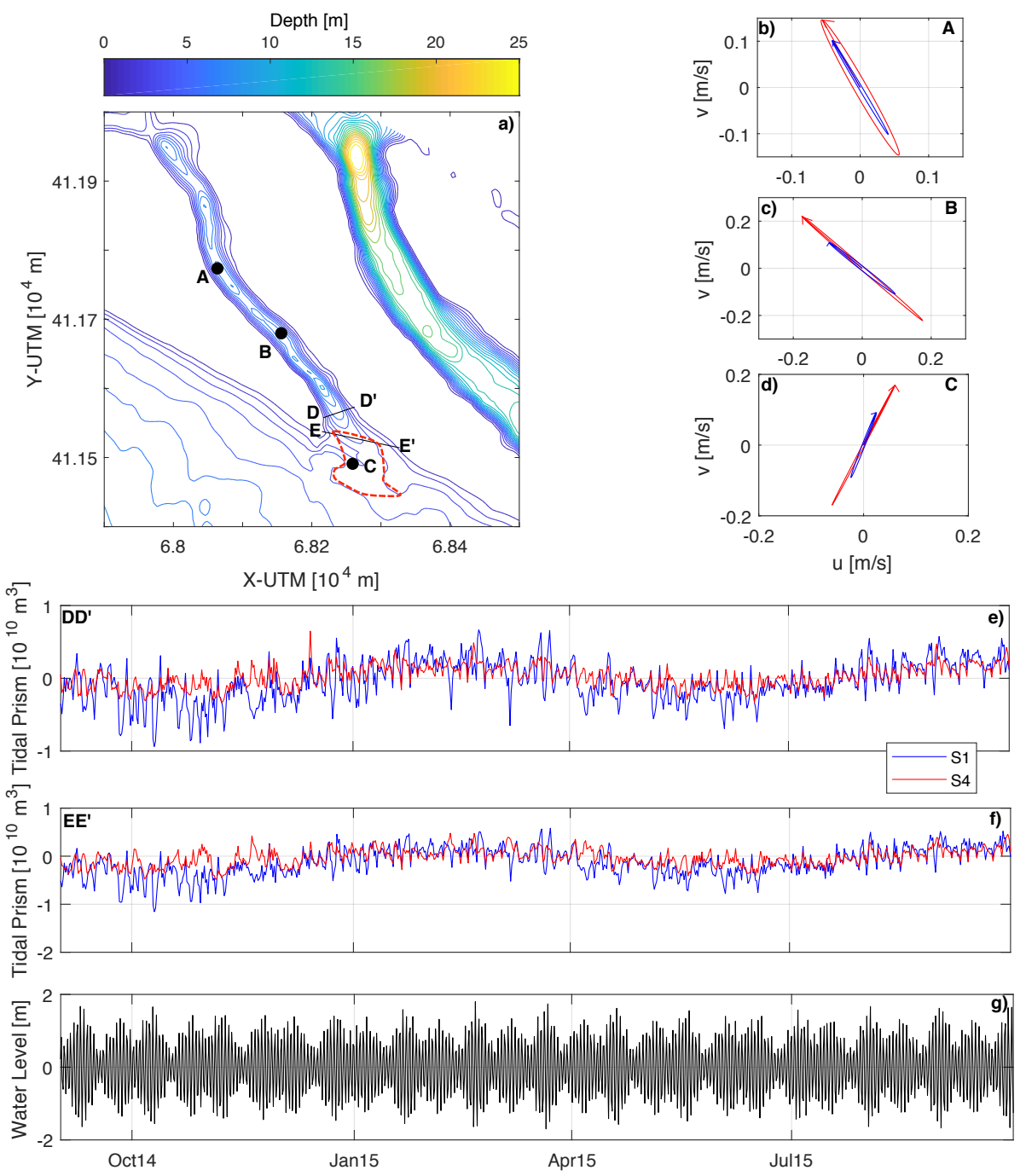

Figure 13: a) Location of the three points A, B and C, sections D-D' and E-E' and shoal removal (red dashed line). b-d) Tidal ellipses at A, B and C (blue and red lines correspond to the initial strategy and the shoaling removal). e-f) Tidal prisms at DD' and E-E', respectively (blue and red lines correspond to the initial strategy and the shoaling removal). g) Water level variation. 